\title{
Ciudades turísticas: ¿sostenibles? Caso Cancún
}

\author{
Pilivet Aguiar Alayola, Christine McCoy Cador, \\ Lucila Zárraga Cano
}

\begin{abstract}
Resumen: La ciudad de Cancún, Quintana Roo, México, se caracteriza por su actividad turística, debido a los atractivos turísticos que ofrece. El objetivo de esta investigación es determinar el nivel de sostenibilidad de las dimensiones urbana, ambiental, fiscal y turística. La metodología de investigación son los resultados obtenidos a partir del modelo de medición de la sostenibilidad y calidad de vida para ciudades turísticas, a través de datos secundarios y primarios, mediante un estudio exploratorio a una muestra de 416 habitantes de la ciudad de Cancún, Q. Roo. Los resultados arrojan que Cancún tiene áreas de mejora para coadyuvar a la sostenibilidad.
\end{abstract}

Palabras clave: calidad de vida, ciudades emergentes, ciudades turísticas, desarrollo, sostenibilidad

Quintana Roo es un estado compuesto por 11 municipios, dividido en tres regiones (sur, zona maya y norte) en donde la zona norte es preponderantemente turística, y está compuesta por los municipios de Cozumel, Solidaridad, Puerto Morelos, Benito Juárez e Isla Mujeres, y las áreas costeras de Lázaro Cárdenas y Tulum. Es una región que cuenta con $90 \%$ de la infraestructura turística de la entidad (INEGI, 2018).

Debido al turismo, las ciudades de mayor crecimiento en el estado son Cancún, Playa del Carmen y Tulum, estas dos últimas conforman la Riviera Maya. Durante el 2017, el número de turistas que arribó al estado fue de 11,522,815, de los cuales 4, 733,549 llegaron a Cancún, lo que representa $77.7 \%$ de ocupación hotelera, y 5, 047,861 a Riviera que corresponde al 82.5\% de ocupación hotelera (SEDETUR, 2017).

La derrama económica en el estado durante 2017 fue de $\$ 8,851.15$ millones de dólares, de los cuales Cancún generó $\$ 4,714.28$ millones y Riviera Maya \$3,180.15 millones de dólares (SEDETUR, 2017). El éxito económico trajo diversas consecuencias, como el acelerado aumento poblacional debido a la inmigración, crecimiento desordenado de las ciudades, el desarrolo de polos urbanos centrados únicamente en el turismo y sus derivados. 
Cancún y la Riviera Maya, viven una segregación del espacio social marcada en la que existe una ocupación desordenada, con fuerte concentración urbana, asentamientos humanos irregulares y sin servicios básicos en dónde observamos una creciente urbanización descapitalizada, siendo la población que ahí habita vulnerable a problemas de salud y desastres hidrometeorológicos, además de problemas sociales como inseguridad, violencia y pobreza.

Esta investigación estudia la ciudad de Cancún como uno de los principales polos turísticos de México ubicada en el Caribe Mexicano. A sus 50 años de existencia Cancún cuenta con una población de 870,322 personas, con un desempleo de solo 3.32\% (INEGI, 2018) y presenta un Índice de Desarrollo Humano de 781 (PNUD, 2014), parámetro establecido por el Programa de las Naciones Unidas para el Desarrollo que incluye factores como salud, educación e ingreso y coloca a la ciudad de Cancún en un nivel alto de desarrollo humano. También posee recursos naturales como las playas, principal atractivo turístico de la zona.

Sin embargo, bajo la lupa del desarrollo, y en especial del desarrollo sostenible la ciudad de Cancún, encontramos elementos para cuestionar su sostenibilidad económica, ya que el $43.3 \%$ de su población percibe entre dos y cinco salarios mínimos (INEGI, 2018), equivalente en promedio a 5,609 pesos mexicanos mensuales en una ciudad considerada este 2020 como una de las más caras del país, según el ranking mundial que presenta Numbeo (2020).

Otro detalle que pone en duda la sostenibilidad en Cancún, es el crecimiento de los asentamientos irregulares en la ciudad en donde los habitantes viven en condiciones de precariedad, sin servicios básicos y cerca del área de pozos de captación de agua para uso humano, con lo que afectan el ecosistema (McCoy \& Aguiar, 2017). Además, en esta ciudad solamente existen $6.1 \mathrm{~m}^{2}$ de zonas verdes por habitante encontraste a los $15 \mathrm{~m}^{2}$ que establece la ONU en su Reporte Nacional de Prosperidad Urbana de México (2019) como medida adecuada para habitantes urbanos.

Los datos anteriores ponen en duda la sostenibilidad de Cancún, por lo que el objetivo de esta investigación es determinar el nivel de sostenibilidad de la ciudad en las dimensiones de sostenibilidad urbana, ambiental, fiscal y turística para coadyuvar a la sostenibilidad.

Las preguntas de investigación que planteamos son: ¿es Cancún un centro turístico sostenible? y ¿qué nivel de calidad de vida provee la ciudad de Cancún? Planteamos responder a estas preguntas a partir de la percepción de sus habitantes, reflejado en su calidad de vida, lo que representa tener bienes y servicios adecuados para las necesidades personales y de la comunidad, mediante datos secundarios y primarios obtenidos a 
través del modelo de medición de la sostenibilidad y calidad de vida para ciudades turísticas.

El presente texto consta de un apartado contextual, detallando las características urbanas de Cancún. Posteriormente presentamos la metodología del modelo de medición de la sostenibilidad y calidad de vida para ciudades turísticas, seguido el marco teórico que da sustento al trabajo. En el apartado de resultados presentaremos los datos obtenidos del modelo, así como de la investigación exploratoria, previo a las conclusiones.

\section{Marco contextual}

La ciudad de Cancún cuenta con una tasa de crecimiento poblacional estimada del $2.5 \%$, lo que representa el $70 \%$ de la totalidad de la población del estado (COESPO Quintana Roo, 2019). El municipio cuenta con una superficie de $1664 \mathrm{~km}^{2}$ y ocupa el $3.27 \%$ del territorio del estado (INEGI, 2017). Su población pasó de 33,273 habitantes en el año de 1980 a 870,322 en el 2018 (CONAVI-SEDATU, 2019), por lo que este crecimiento acelerado ha incrementado drásticamente la densidad de población en el municipio, la cual pasó de ser de 19.35 habitantes $/ \mathrm{km}^{2}$ en el año 1980 a 298.13 habitantes $/ \mathrm{km}^{2}$ para el año 2005, y para 2010 se reportó en 402.18 habitantes $/ \mathrm{km}^{2}$ (McCoy, 2015). La densidad actual es de 523 habitantes $/ \mathrm{km} 2$ (CONAVI-SEDATU, 2019).

Como señala el estudio de actualización del Programa de Desarrollo Urbano del Centro de Población de Cancún (2018), este municipio es el principal polo turístico de sol y playa de México. El modelo de desarrollo empleado para su conceptualización estuvo basado en un amplio estudio de capacidad de carga para conocer exactamente lo que el terreno a desarrollar soportaba en cuanto a la infraestructura necesaria, las plantas tratadoras de agua, las abastecedoras de agua potable y luz e inclusive la dimensión del relleno sanitario basado en una determinada cantidad de cuartos y un tamaño de población fija en el centro de la ciudad a un horizonte de 30 años (FONATUR, 1982).

Dicho estudio también contemplaba la satisfacción de las necesidades de infraestructura y otros servicios de la población local como son escuelas, una clínica hospitalaria del Instituto Mexicano del Seguro Social, mercados y por supuesto un aeropuerto internacional. Según el Plan Maestro de 1982, el desarrollo urbano y turístico de Cancún fue dotado de infraestructura básica que le diera la oportunidad de crecer y atender las necesidades de la población naciente tanto local como turistas.

Fue la primera zona turística en contar con un plan maestro de desarrollo que daría vida a los Centros Integralmente Planeados (CIP) en 
México, con una visión innovadora, porque contempló un polo turístico sostenible y equilibrado con oportunidades de empleo e inversión, siempre en armonía con el entorno natural (McCoy \& Sosa, 2016).

Con esta planeación, podríamos inferir que el destino es sostenible y que provee de una calidad de vida. La ciudad fue creada con la idea de "generar desarrollo" y desde el punto de vista turístico Cancún es todo un éxito, ya que es considerado como el mejor destino turístico de sol y playa de Latinoamérica. Sin embargo, al profundizar en los datos sociodemográficos y ambientales observamos que un destino importante para vacacionar puede convertirse en un lugar difícil para vivir. Córdoba (2019) menciona que es una ciudad dividida en dos, la zona hotelera lugar para los turistas y la ciudad de Cancún para las personas que trabajan ahí, ambas áreas están separadas y diseñadas para ser invisibles entre cada una.

De esta forma el proceso acumulativo continúa ante un plan de desarrollo urbano que quedó rebasado, limitado e insuficiente, donde uno de los elementos más deficitarios del panorama urbano de la ciudad es la existencia de zonas urbanas que segregan a grupos poblacionales y que limitan la integración de los pobladores de la ciudad.

En relación al empleo, la población económicamente activa en el municipio de Benito Juárez es del 61.73\%. De este total, en 2018 el 96.68\% fue considerada población ocupada y solo el 3.32\% desocupada, lo que representó una cifra mínima de desempleo en la entidad (Secretaría de Desarrollo del Gobierno de Quintana Roo, 2020).

En el aspecto salarial de acuerdo a datos de Gobierno del Estado (2018), $35.92 \%$ de los asalariados perciben ingresos que oscilan entre menos de un salario mínimo y hasta dos salarios mínimos, $43.3 \%$ perciben entre dos y cinco salarios mínimos, solamente el $5.87 \%$ percibe más de cinco salarios mínimos.

Sin embargo, a pesar de ofrecer remuneraciones bajas, la estructura salarial de Cancún es atractiva para los trabajadores de otros estados, que en su lugar de origen perciben salarios y prestaciones menores, por lo que deciden migrar hacia esta zona (Aguiar, 2018). Esto ha disparado el crecimiento de asentamientos irregulares, existiendo en la ciudad actualmente 138, donde sus habitantes viven en condiciones de precariedad (SEDETU, 2019).

\section{Metodología}

La metodología de la investigación se fundamenta en el modelo de medición de la sostenibilidad y calidad de vida para ciudades turísticas (McCoy 


\section{Modelo de medición de la \\ Turística sostenibilidad y
calidad de vida
para ciudades}

Fiscal

Figura 1 - Modelo de la medición de la sostenibilidad y calidad de vida para ciudades turísticas

Fuente: elaboración propia a partir de McCoy y Aguiar (2017)

\& Aguiar, 2017) (figura 1), basado en la Iniciativa de Ciudades Emergentes y Sostenibles como una propuesta institucional del Banco Interamericano de Desarrollo (2014), para apoyar a mejorar la calidad de vida de sus ciudadanos y su sostenibilidad. Está compuesto por las tres dimensiones la ambiental, urbana, fiscal. McCoy y Aguiar añaden una cuarta dimensión, la turística, que Ludger Brenner propuso en 1999.

El modelo de medición de la sostenibilidad y calidad de vida para ciudades turísticas se basa en un análisis cuantitativo, utilizando indicadores obtenidos en su mayoría con información secundaria, provenientes de fuentes oficiales como INEGI, CONAPO, Secretaría de Economía, y Gobierno del Estado, durante los años 2016 y 2017. El modelo compara los valores estimados para cada indicador con valores relacionados con índices convenidos internacionalmente o con puntos de referencia de ciudades similares en la región o el país establecidos por el Banco Interamericano de Desarrollo. Los indicadores señalan en verde si la gestión es 
adecuada o buena, en amarillo si el tema presenta alguna dificultad en su servicio o gestión y en rojo si el servicio o gestión es deficiente, de acuerdo con el rango en el que se ubica el valor indicado.

Posteriormente se analiza desde la perspectiva de la ciudadanía a partir de datos primarios, recolectada mediante una encuesta estructurada, de tipo exploratorio que generan conocimientos que definen la situación problemática. A un muestreo no probabilístico, proceso en el que se desconoce la probabilidad de elegir cada unidad de muestreo, y en donde obtuvimos 416 encuestas de habitantes de la ciudad de Cancún, realizado a finales de noviembre del 2017, en 110 diferentes supermanzanas y regiones (colonias de estrato socioeconómicos $\mathrm{D}, \mathrm{D}+\mathrm{C}, \mathrm{C}+$ ) de la ciudad, con el apoyo de estudiantes de licenciatura de la Universidad del Caribe. Los datos de la investigación primaria fueron analizados con el programa estadístico SPSS.

Para integrar las cuatro dimensiones e interrelacionar los indicadores utilizamos un tablero para una visualización sencilla. El modelo analiza cada indicador de manera individual o a los conjuntos de indicadores de manera interrelacionada.

La dimensión de sostenibilidad urbana (tabla 1), abarca factores físicos y públicos, los cuales están ligados directamente con los habitantes de la comunidad, como uso de suelo, salud, educación, conectividad, empleo, competitividad de la economía, movilidad y transporte, desigualdad urbana y seguridad.

La dimensión de sostenibilidad ambiental (tabla 2), cubre factores que manipulan los recursos e indican de qué manera afectan al ecosistema. Implica proveer agua y saneamiento, crear espacios recreativos y culturales, tratar y reciclar los residuos sólidos, lograr la eficiencia energética e introducir energías limpias y renovables, y desarrollar una gestión del riesgo de desastres. En esta dimensión no incluimos el manejo de playas ni de humedales ya que esto se relaciona directamente con los destinos de sol y playa, y no con otros tipos de ciudades turísticas.

Dimensión de sostenibilidad fiscal (tabla 3), están relacionados con factores financieros y administrativos, los cuales el gobierno regula, por ejemplo modernizar la gestión financiera y fiscal y organizar los servicios públicos locales e implementar la gestión por objetivos.

La dimensión turística (tabla 4), enfoca la perspectiva tanto de la población que vive en el destino turístico como de los turistas, miembros activos de la actividad. Implica la participación de la población local, beneficios económicos percibidos del turismo y el aseguramiento de un mercado laboral. 


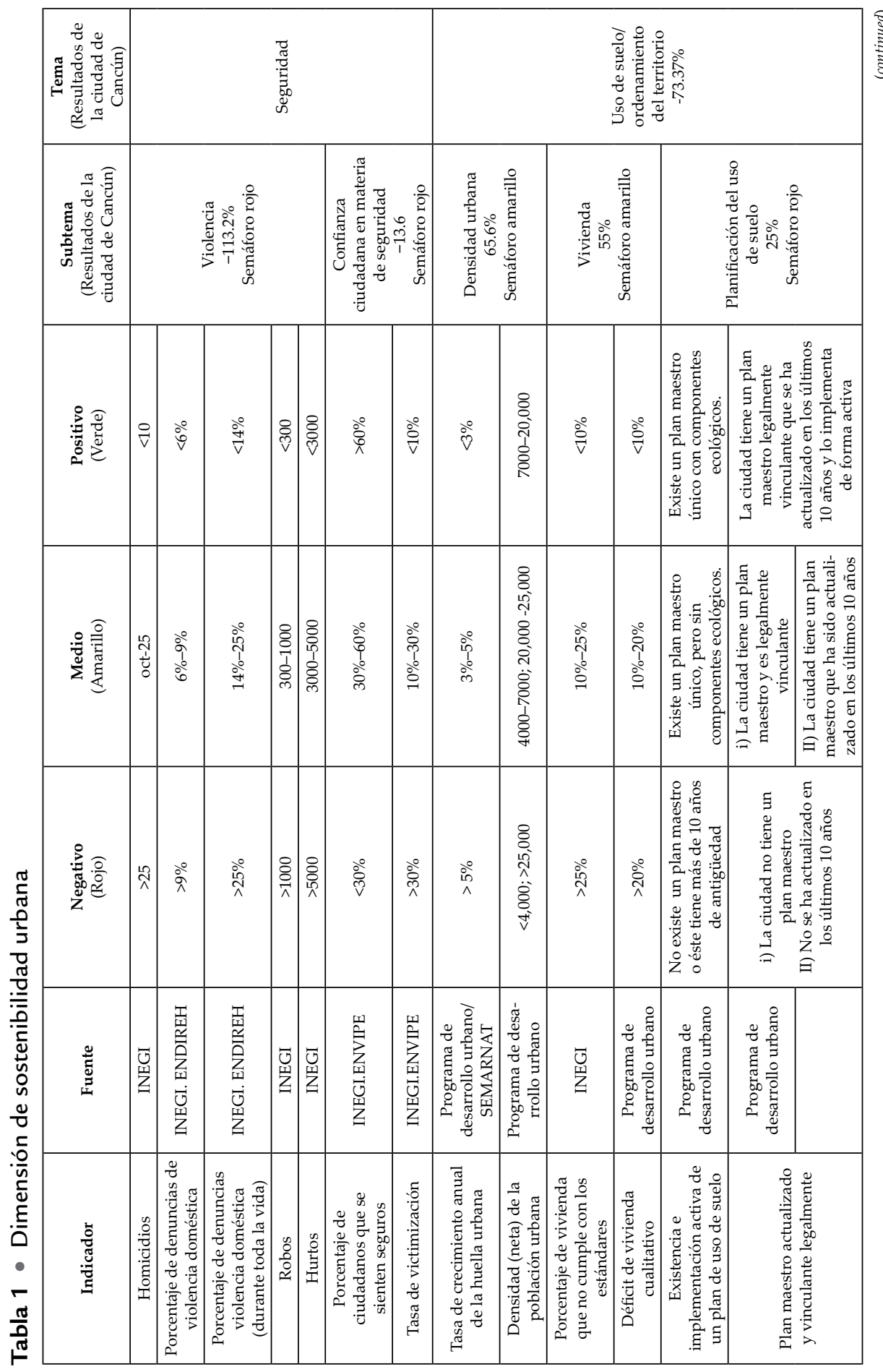




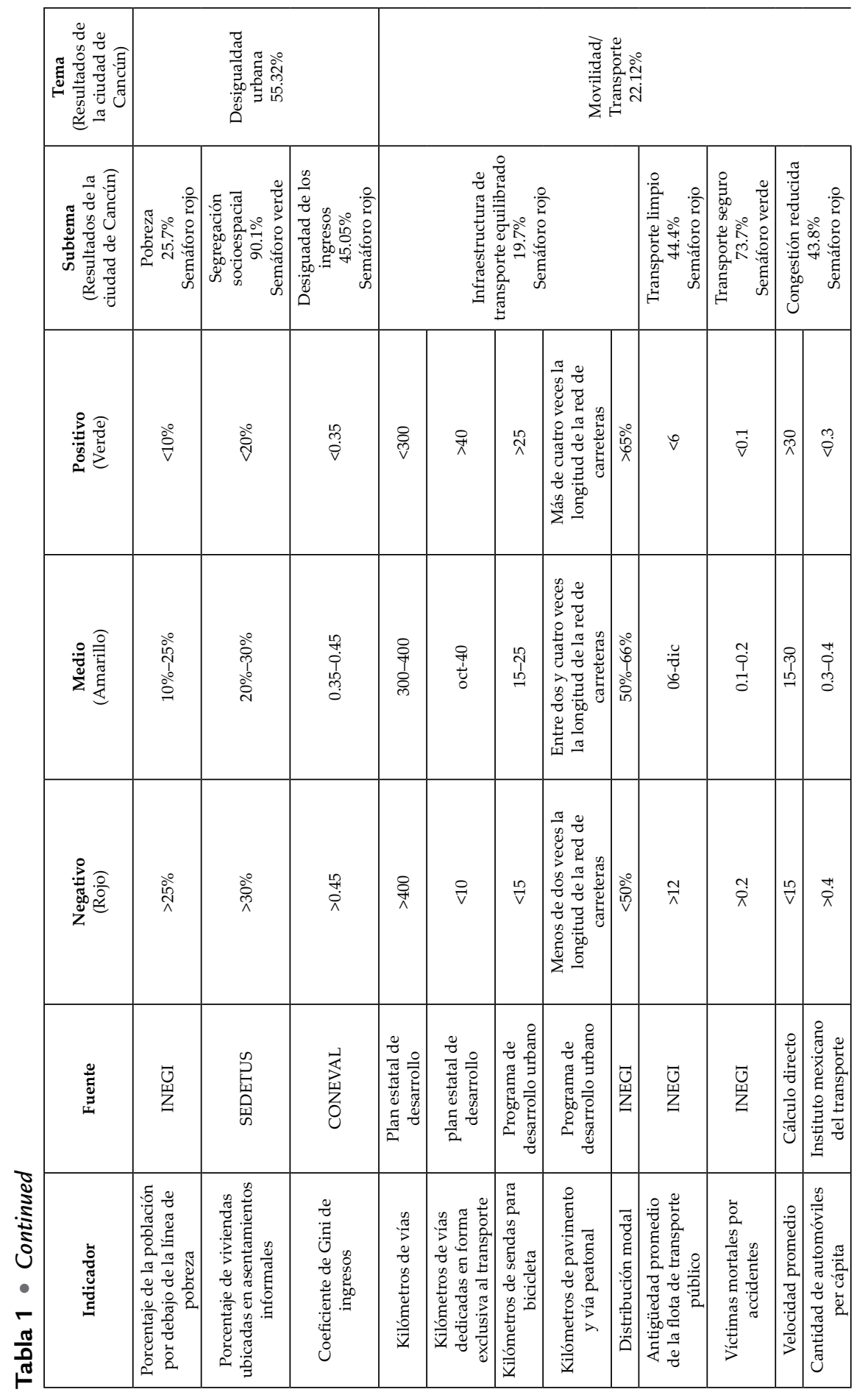




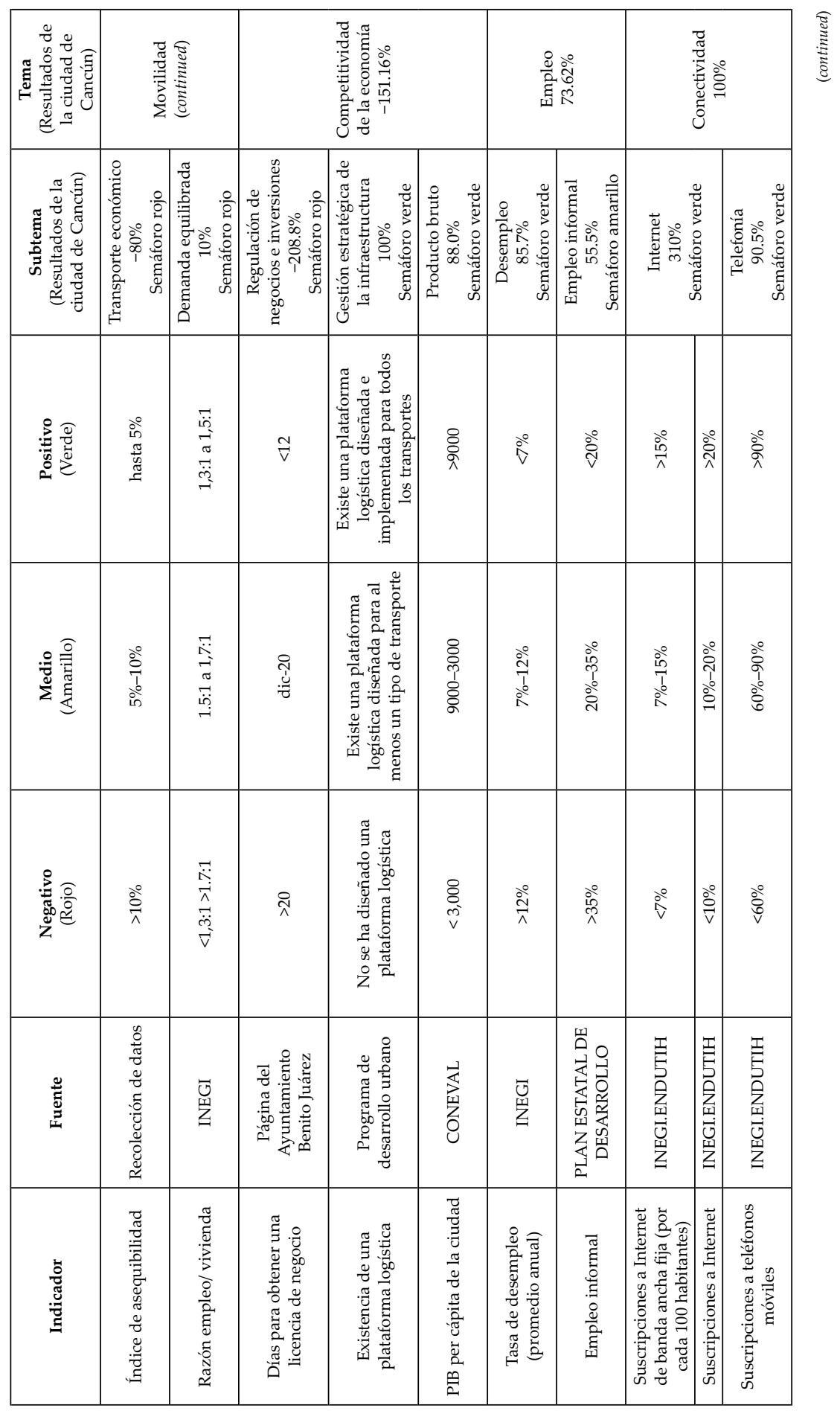




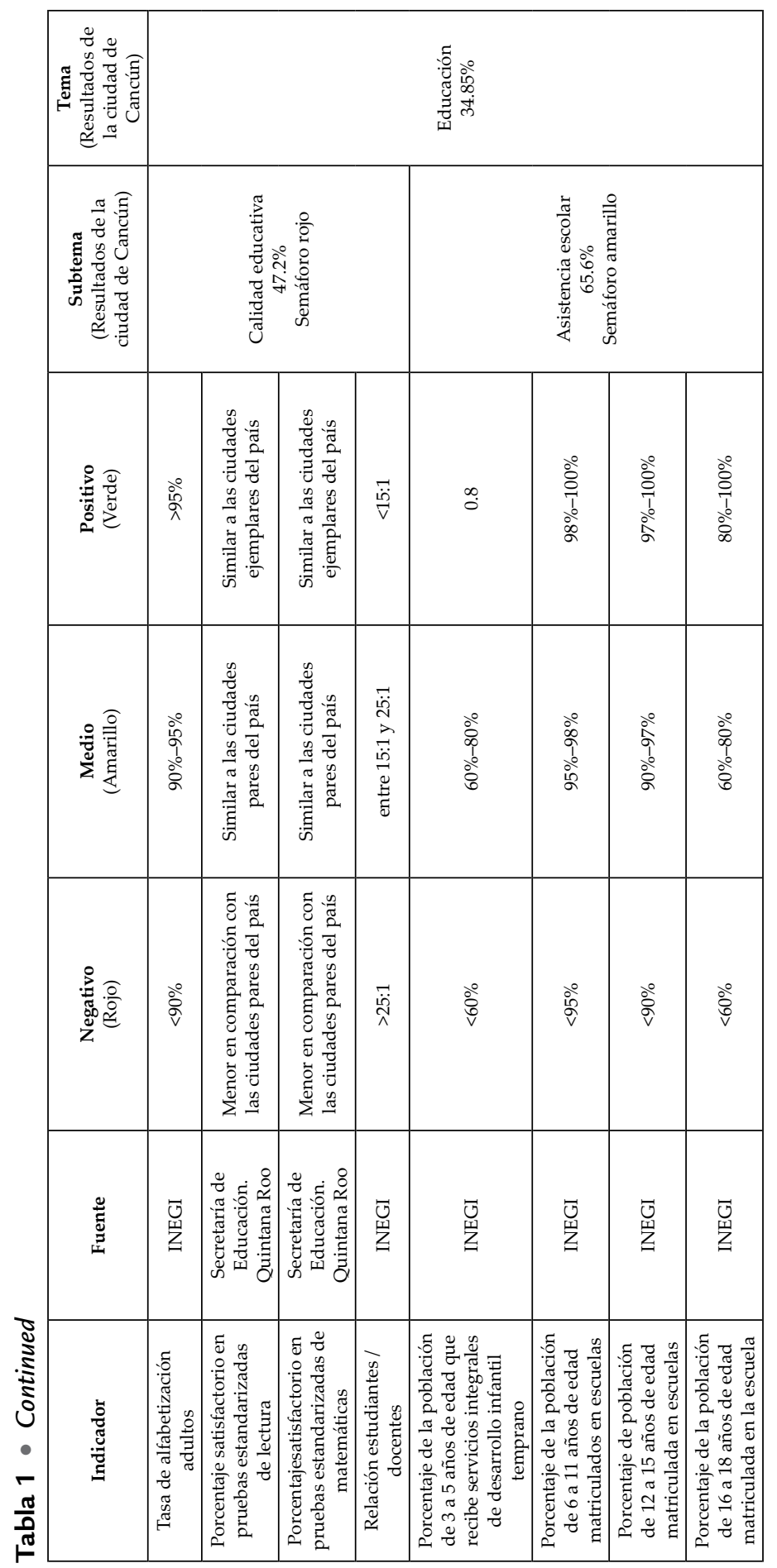




\begin{tabular}{|c|c|c|c|c|c|c|}
\hline 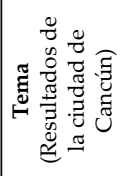 & \multicolumn{4}{|c|}{ 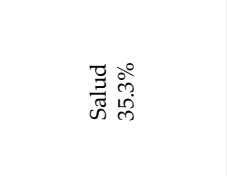 } & \multicolumn{2}{|c|}{ 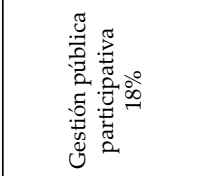 } \\
\hline 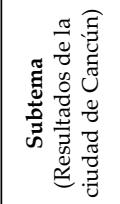 & \multicolumn{4}{|c|}{ 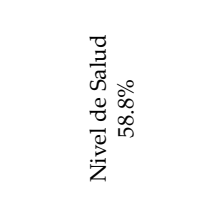 } & \multicolumn{2}{|c|}{ 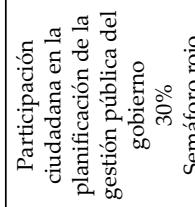 } \\
\hline 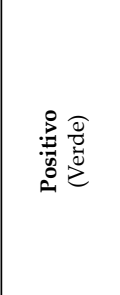 & $\underset{\lambda}{\stackrel{\Delta}{\lambda}}$ & $\stackrel{R}{\lambda}$ & L्र & $\stackrel{\nabla}{\nabla}$ & 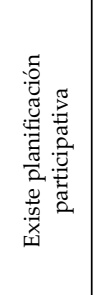 & 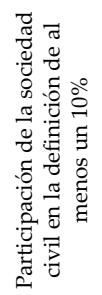 \\
\hline 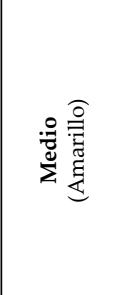 & $\mid \begin{array}{l}2 \\
\hat{1} \\
d \\
R\end{array}$ & $\begin{array}{l}\text { R } \\
\text { ti }\end{array}$ & $\begin{array}{l}\stackrel{0}{1} \\
\stackrel{1}{2}\end{array}$ & 㜽 & 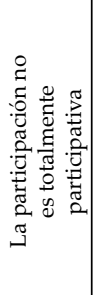 & 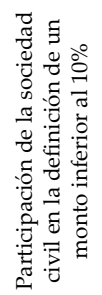 \\
\hline 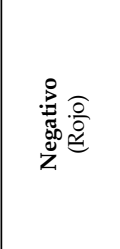 & $\stackrel{R}{\mathrm{v}}$ & $\underset{\mathrm{V}}{\mathrm{O}}$ & $\stackrel{R}{\mathrm{v}}$ & क्र & 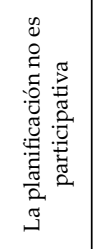 & 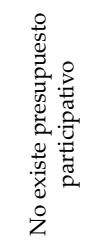 \\
\hline & \begin{tabular}{|l}
$\bar{y}$ \\
II \\
$Z$
\end{tabular} & $\begin{array}{l}\text { ت } \\
\text { 岁 }\end{array}$ & 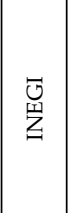 & $\begin{array}{l}\text { ⿹ } \\
\text { 岁 }\end{array}$ & 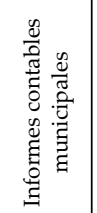 & 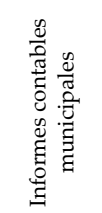 \\
\hline 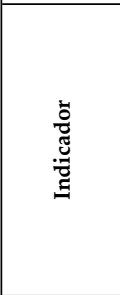 & 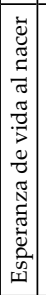 & 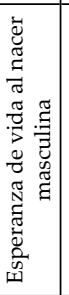 & 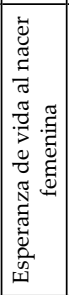 & 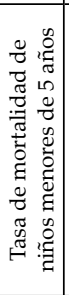 & 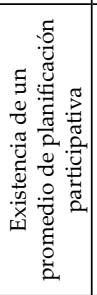 & 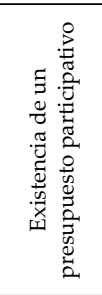 \\
\hline
\end{tabular}




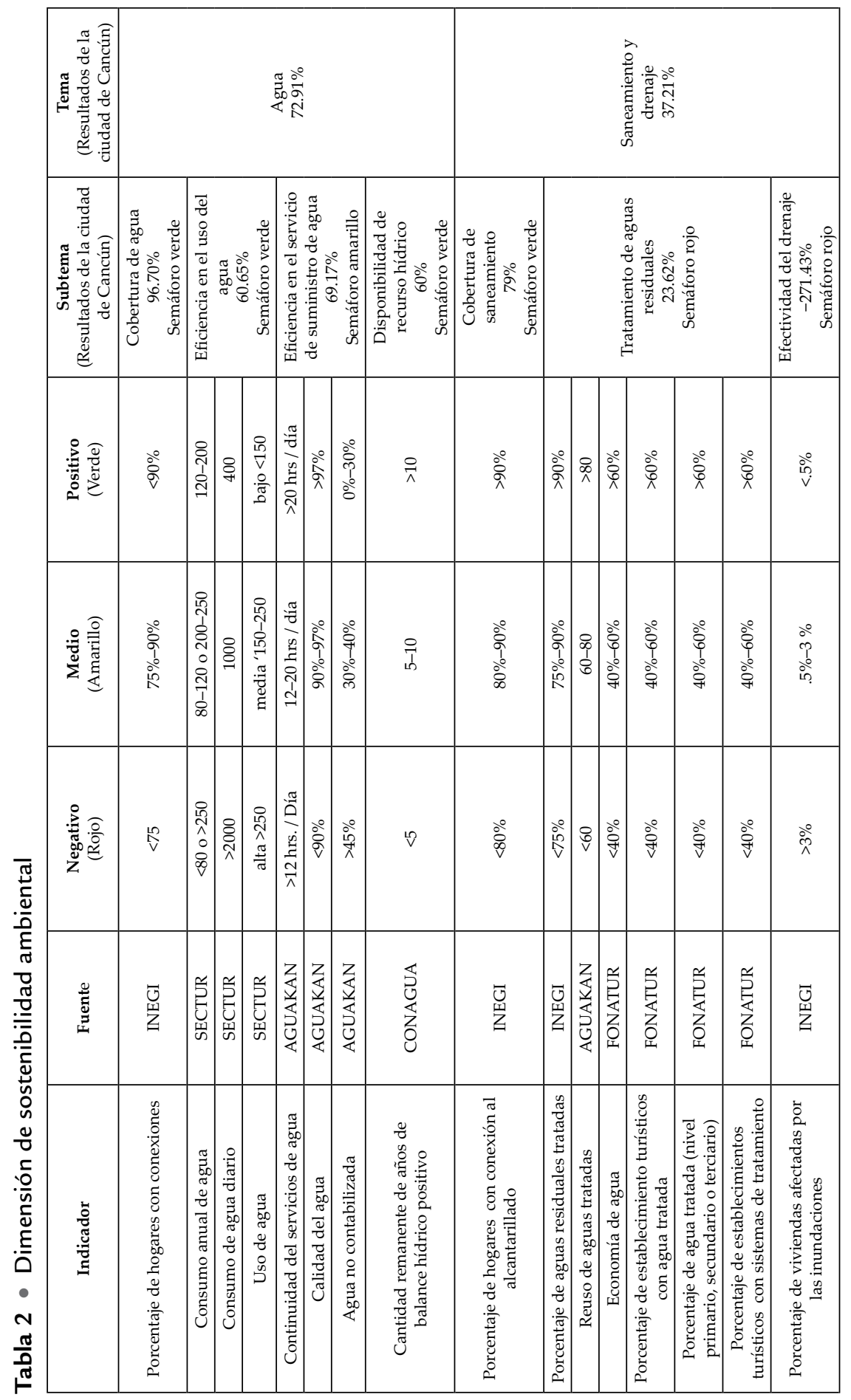




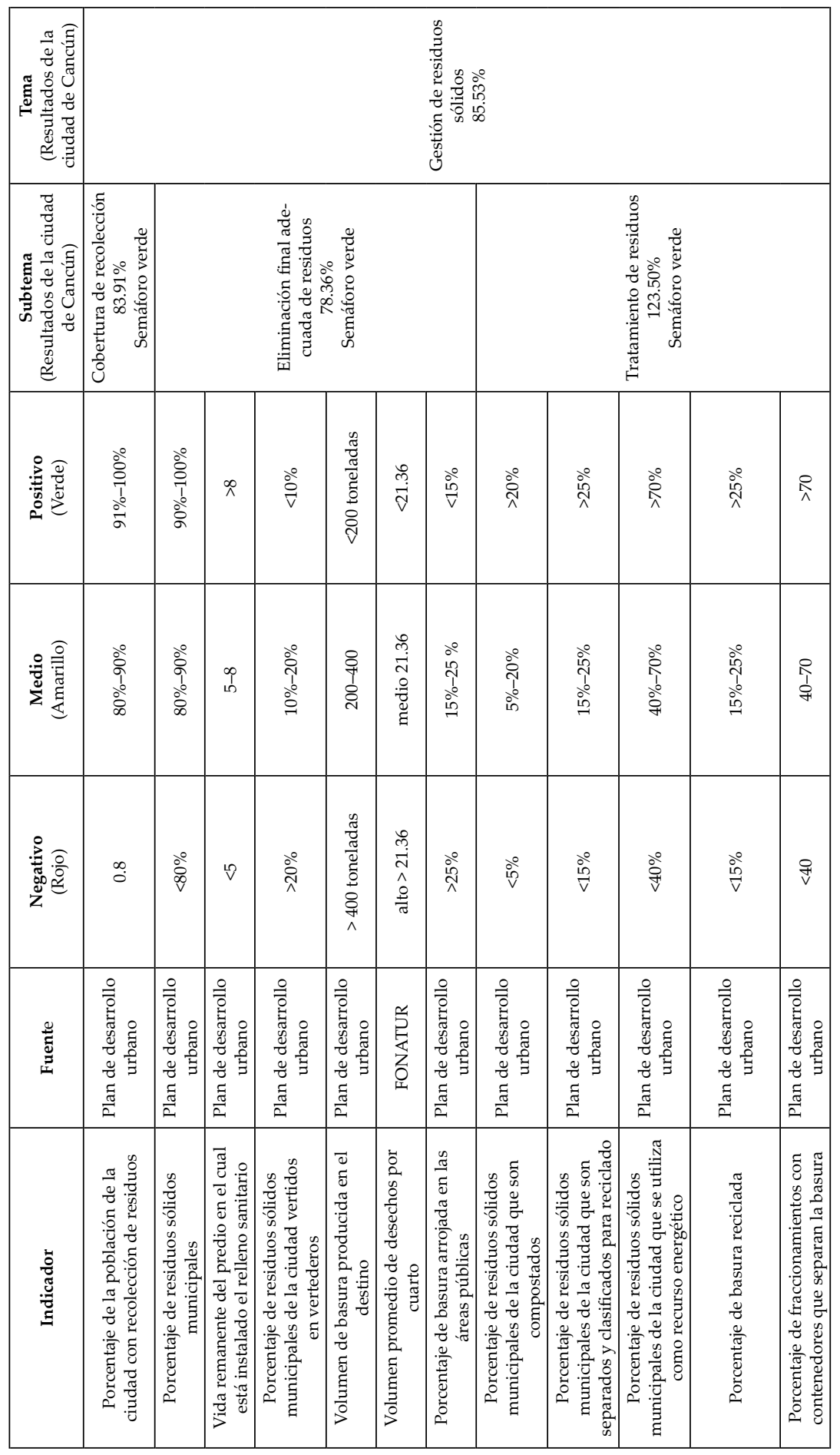




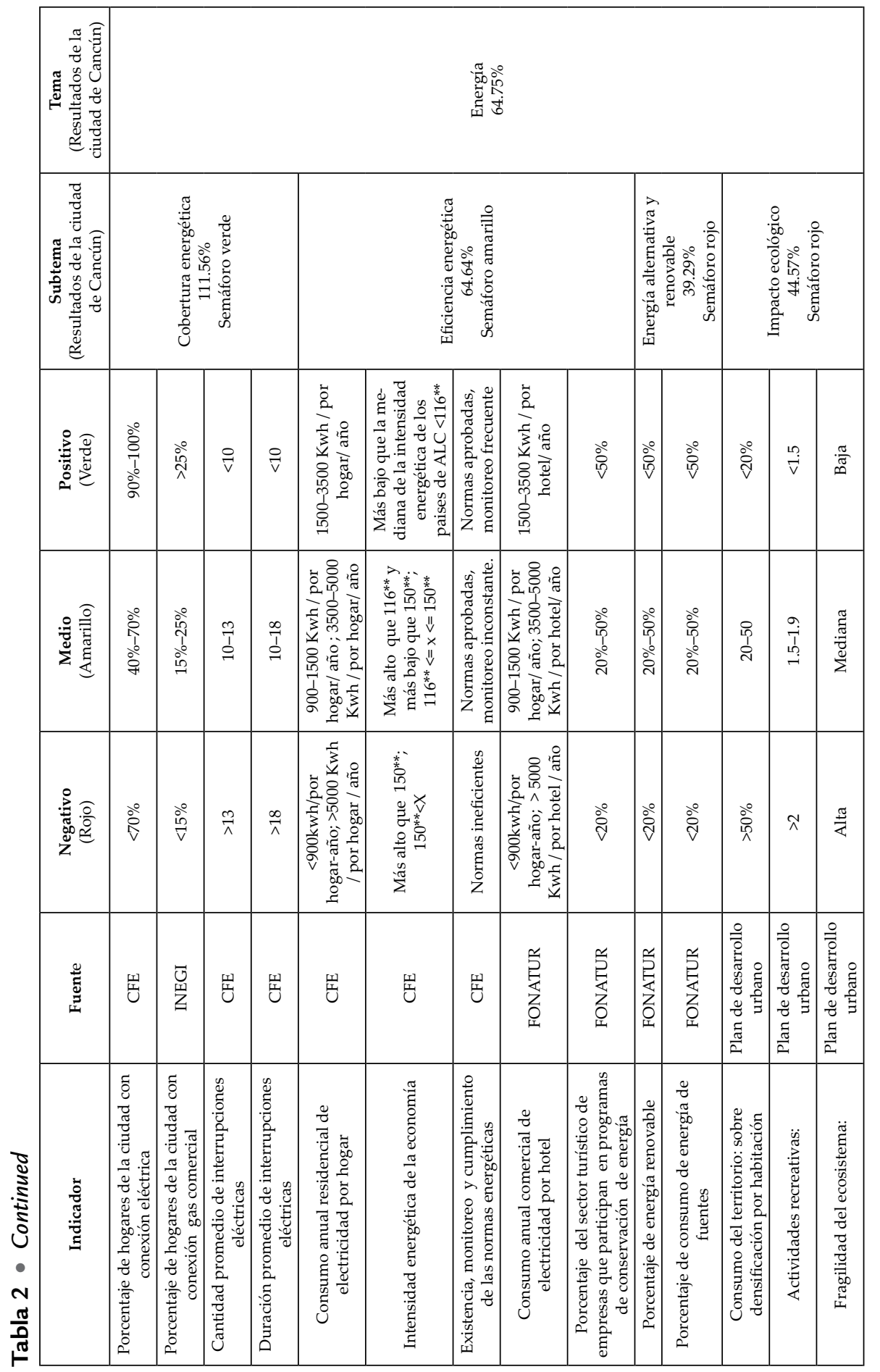




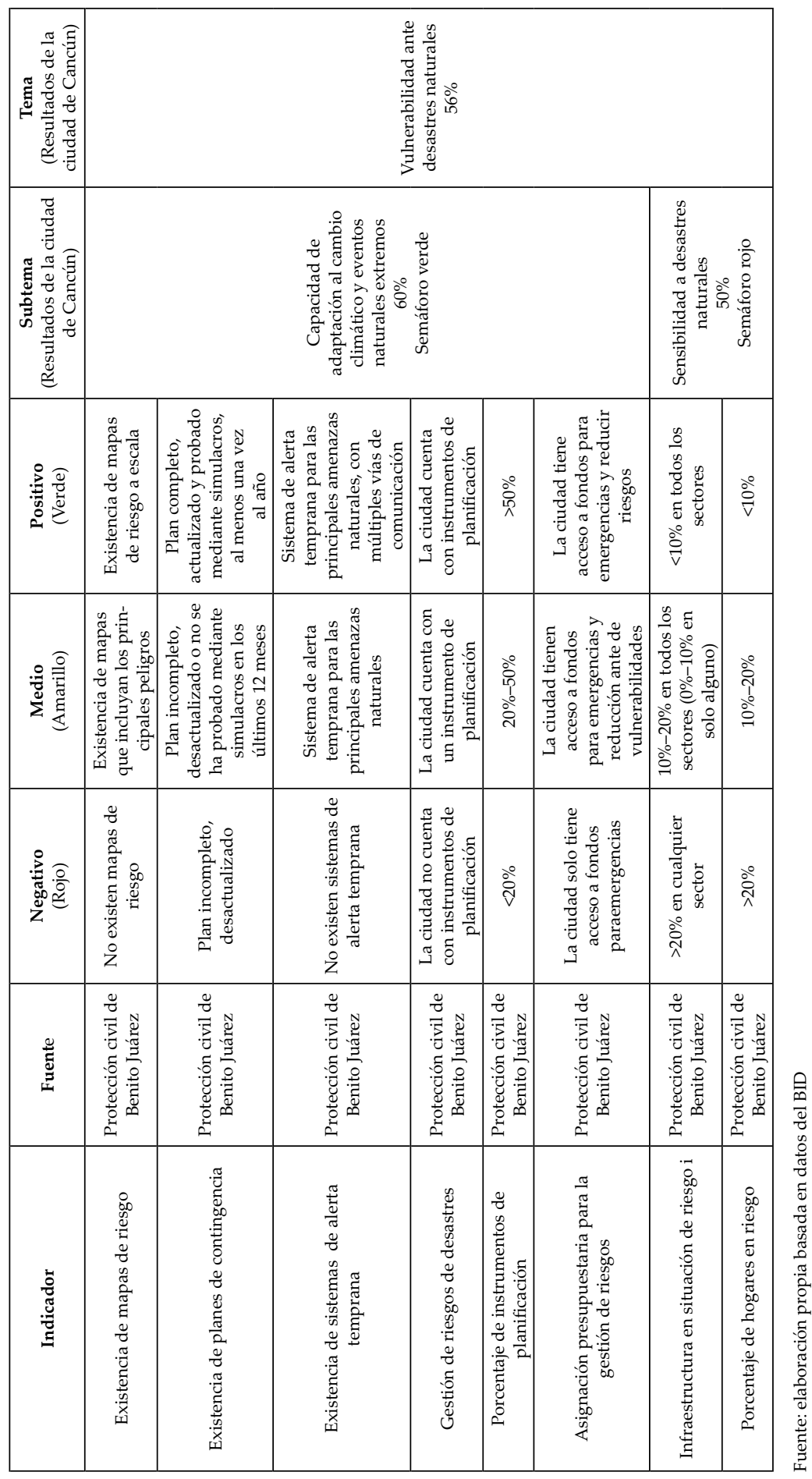




\begin{tabular}{|c|c|c|c|c|c|c|c|c|c|c|c|}
\hline 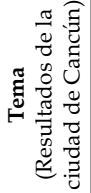 & & & \multicolumn{3}{|c|}{ 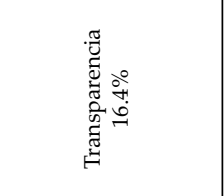 } & \multicolumn{6}{|c|}{ 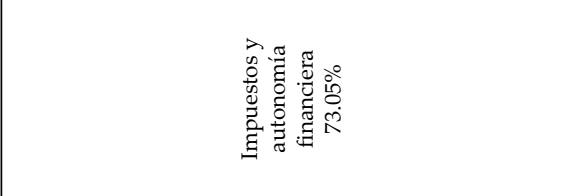 } \\
\hline 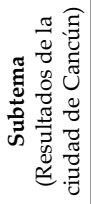 & \multicolumn{2}{|c|}{ 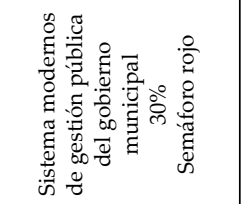 } & \multicolumn{3}{|c|}{ 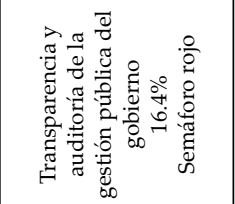 } & \multicolumn{4}{|c|}{ 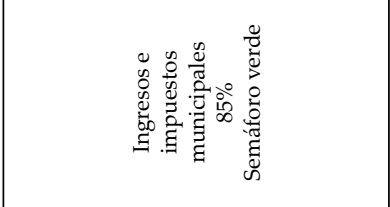 } & \multicolumn{2}{|c|}{ 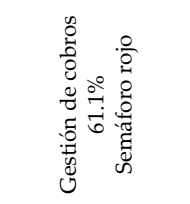 } \\
\hline 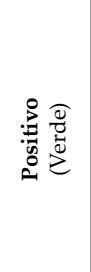 & 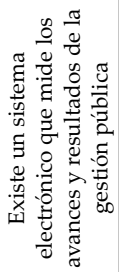 & 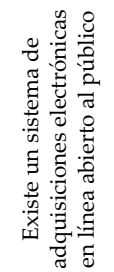 & $\begin{array}{l}0 \\
\dot{1}\end{array}$ & 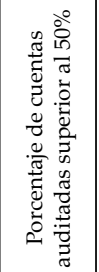 & - & 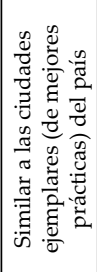 & 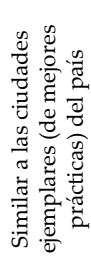 & 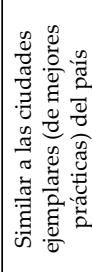 & 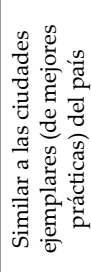 & @̊̀̊ & 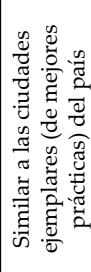 \\
\hline 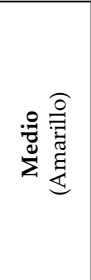 & 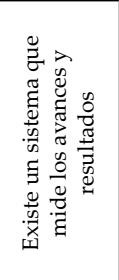 & 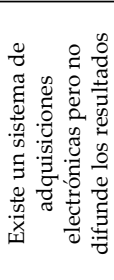 & \begin{tabular}{|c|} 
\\
\\
0 \\
$\dot{0}$ \\
0 \\
$\dot{m}$ \\
$\dot{m}$
\end{tabular} & 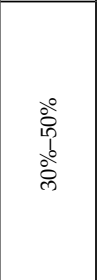 & 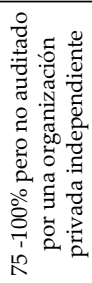 & 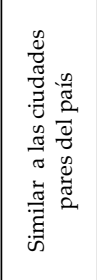 & 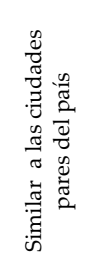 & 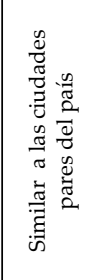 & 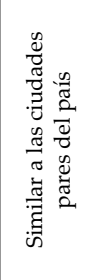 & 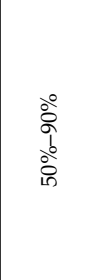 & 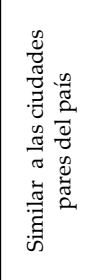 \\
\hline 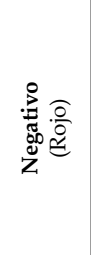 & 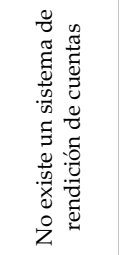 & 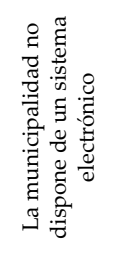 & $\begin{array}{l}\dot{0} \\
\dot{v}\end{array}$ & ஓें & $\stackrel{\stackrel{\circ}{\mathrm{i}}}{\mathrm{V}}$ & 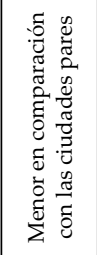 & 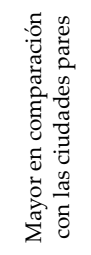 & 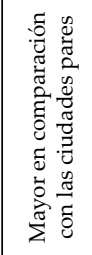 & 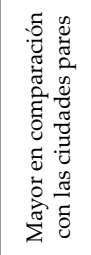 & $\stackrel{\circ}{\stackrel{8}{V}}$ & 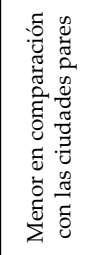 \\
\hline 䒕 & 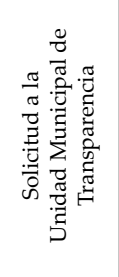 & 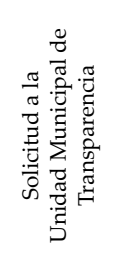 & & 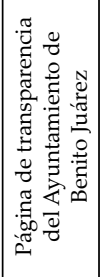 & 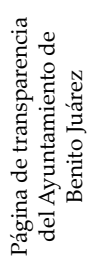 & 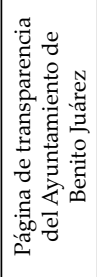 & 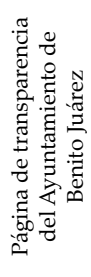 & 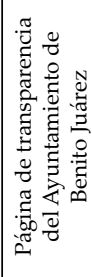 & 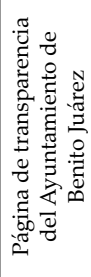 & 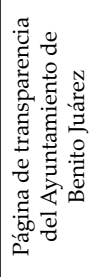 & 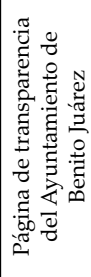 \\
\hline 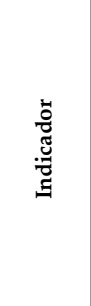 & 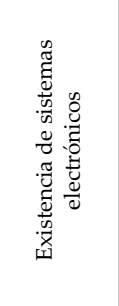 & 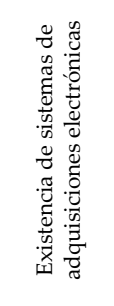 & 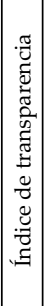 & 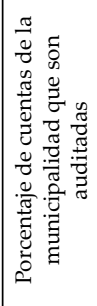 & 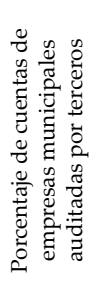 & 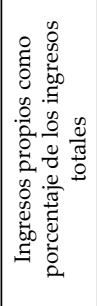 & 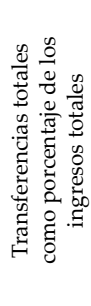 & 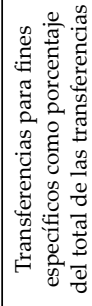 & 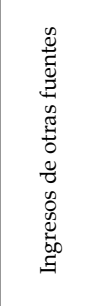 & 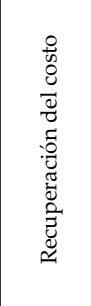 & 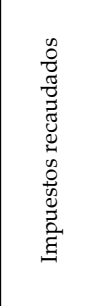 \\
\hline
\end{tabular}




\begin{tabular}{|c|c|c|c|c|c|c|c|c|}
\hline 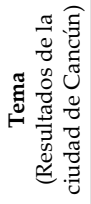 & \multicolumn{5}{|c|}{ 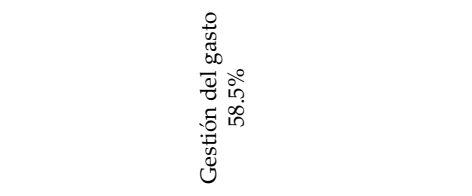 } & \multicolumn{3}{|c|}{ 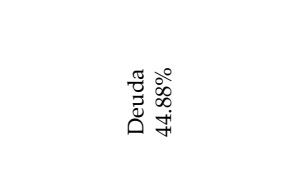 } \\
\hline 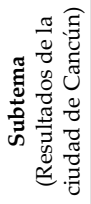 & \multicolumn{5}{|c|}{ 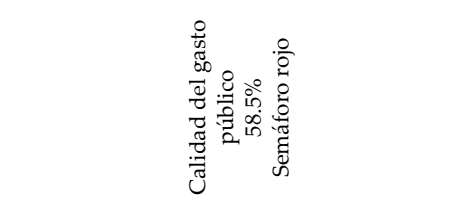 } & 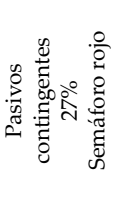 & \multicolumn{2}{|c|}{ 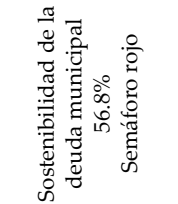 } \\
\hline 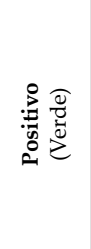 & 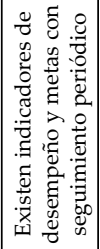 & 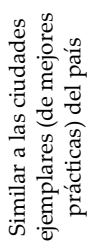 & 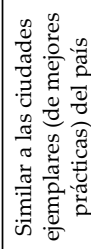 & 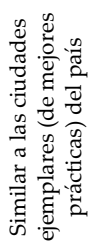 & 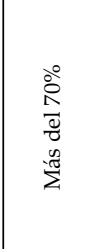 & ஓें & 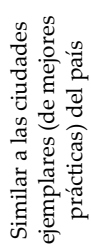 & 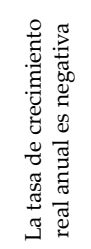 \\
\hline 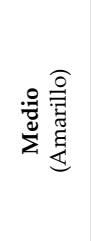 & 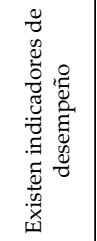 & 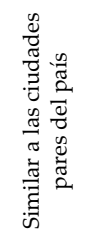 & 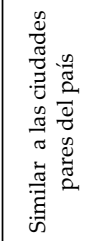 & 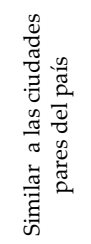 & 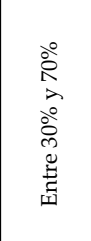 & $\begin{array}{l}\stackrel{0}{0} \\
\vdots \\
\vdots \\
\circ\end{array}$ & 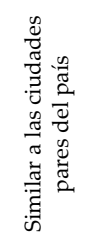 & 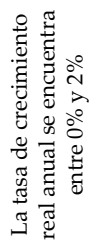 \\
\hline 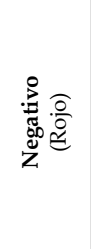 & 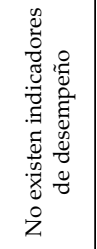 & 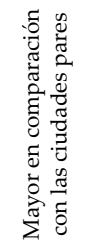 & 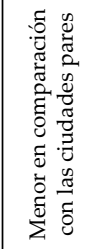 & 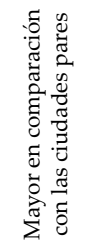 & 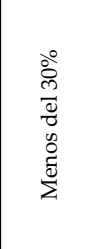 & $\stackrel{\circ}{\circ}$ & 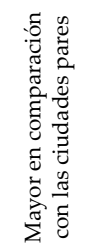 & 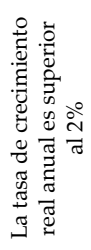 \\
\hline 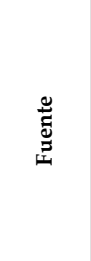 & 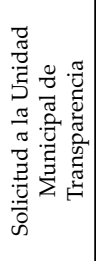 & 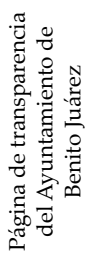 & 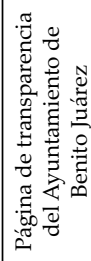 & 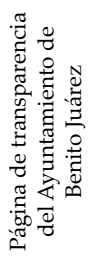 & 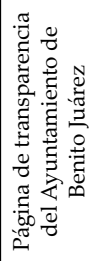 & 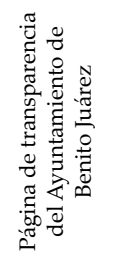 & 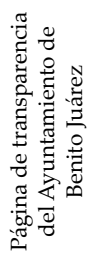 & 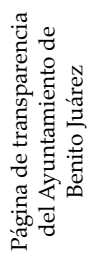 \\
\hline 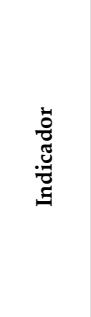 & 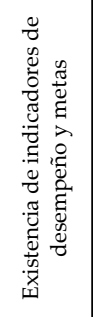 & 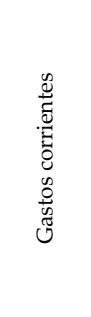 & 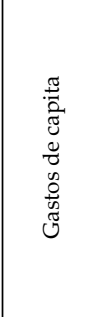 & 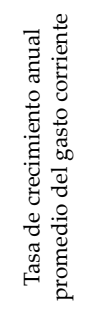 & 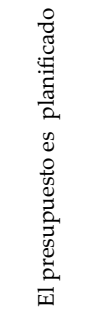 & 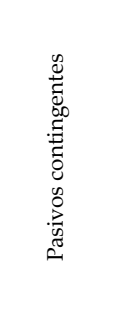 & 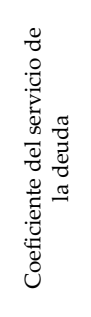 & 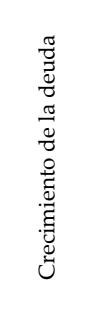 \\
\hline
\end{tabular}




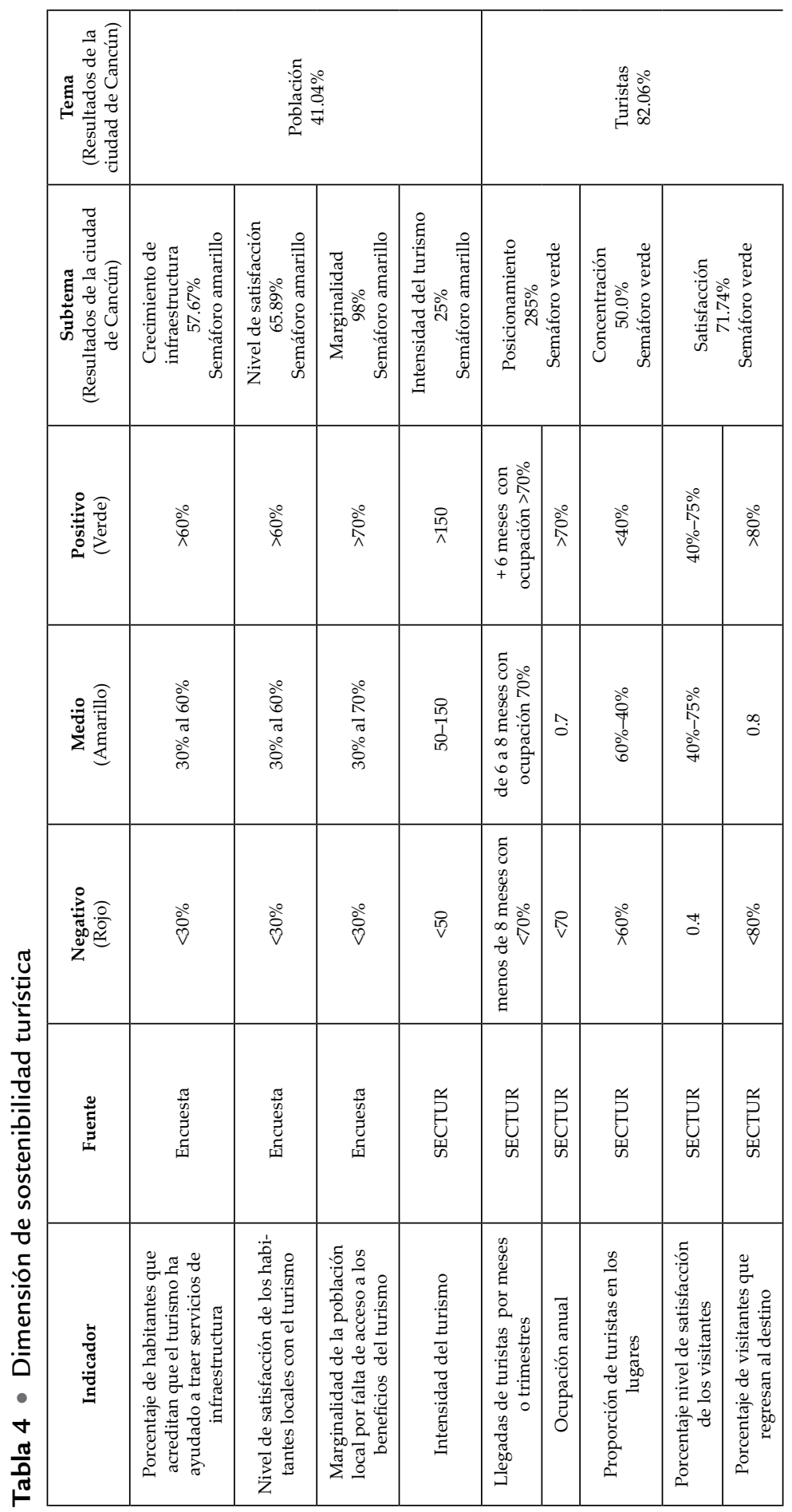




\begin{tabular}{|c|c|c|c|c|c|c|c|}
\hline 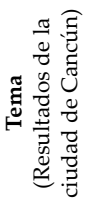 & \multicolumn{7}{|c|}{ 苞 } \\
\hline 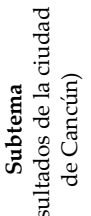 & 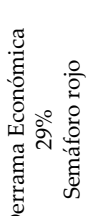 & \multicolumn{6}{|c|}{ 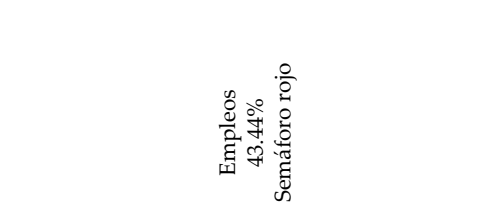 } \\
\hline 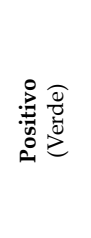 & 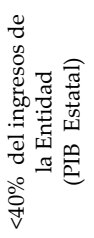 & 总 & $\pi$ & 웃 & 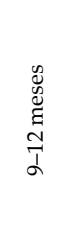 & 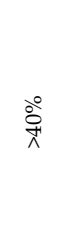 & i \\
\hline 谞 & 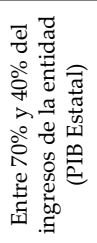 & $\begin{array}{l}\text { 今े } \\
\text { !े } \\
\text { वें }\end{array}$ & $\vec{b}$ & $\begin{array}{l}\text { iें } \\
\text { ì } \\
\stackrel{\text { वें }}{ }\end{array}$ & 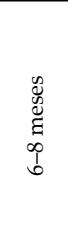 & $\begin{array}{l}\text { 今े } \\
\stackrel{+}{0} \\
\stackrel{े}{0}\end{array}$ & j \\
\hline 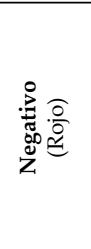 & 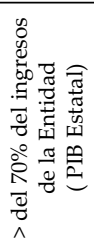 & ते & $\stackrel{\bullet}{v}$ & $\stackrel{\text { ڤे }}{\mathrm{V}}$ & 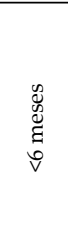 & ○ें & ? \\
\hline 节 & 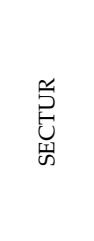 & $\begin{array}{l}\text { 式 } \\
\text { 罗 }\end{array}$ & 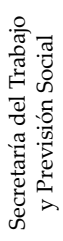 & 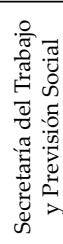 & 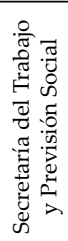 & 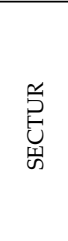 & 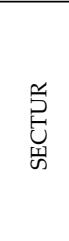 \\
\hline 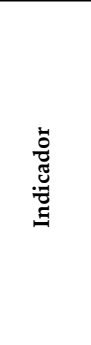 & 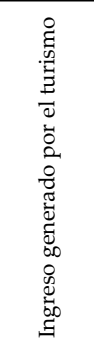 & 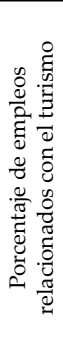 & 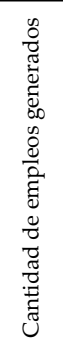 & 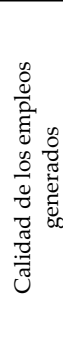 & 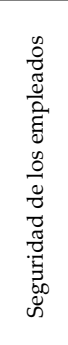 & 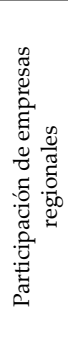 & 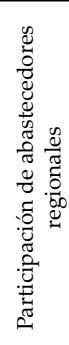 \\
\hline
\end{tabular}




\section{Estructuración de datos}

Estructuramos en una hoja de cálculo los indicadores de manera alfanumérica para considerarlos como nuevas variables. Los indicadores de las cuatro dimensiones están en función a la variable calidad de vida, por lo que fue necesario ponderarlas para determinar el nivel de importancia (esta ponderación fue realizada por expertos en el tema). Posteriormente propusimos un modelamiento matemático para el índice general de calidad de vida.

En donde:

$$
C V=\frac{P^{\alpha} \alpha+P^{\beta} \beta+P^{\theta} \theta+P^{\varepsilon} \varepsilon}{(\alpha+\beta+\theta+\varepsilon)_{100 \text { percent }}}
$$

$\mathrm{CV}=$ Calidad de vida

$\alpha=$ Sustentabilidad ambiental

$\beta=$ Sustentabilidad turística

$\theta=$ Sustentabilidad urbana

$\varepsilon=$ Sustentabilidad fiscal

$P^{i}=$ Ponderación inicial asignada a cada uno de los niveles de jerarquización.

Esta modelamiento matemático expresa el índice de calidad de vida, comprimiendo todos los indicadores en uno solo estandarizado con un valor de 0 a 100.

Cada una de las dimensiones esta desglosada en la sumatoria de cada uno de los indicadores de cada tema por su ponderación y esto también es aplicado a los subtemas e indicador respectivamente.

Fórmula general para la dimensión ambiental:

$$
\alpha=\sum P^{A_{i j}} A_{i j}+\sum P^{B_{i j} B_{i j}}+\sum P^{C_{i j}} C_{i j} \ldots
$$

Fórmula general para la dimensión turística:

$$
\left.\beta=\sum P^{H_{i j} H_{i j}}+\sum P^{I_{i j}} I_{i j}+\sum P^{I_{i j}}\right]_{i j} \ldots
$$

Fórmula general para la dimensión urbana:

$$
\theta=\sum P^{Q_{i j}} Q_{i j}+\sum P^{R_{i j} R_{i j}}+\sum P^{S_{i j}} S_{i j} \cdots
$$

Fórmula general para la dimensión fiscal:

$$
\varepsilon=\sum P^{X_{i j}} X_{i j}+\sum P^{Y_{i j}} Y_{i j}+\sum P^{Z_{i j}} Z_{i j} \cdots
$$




\section{Marco teórico}

A continuación presentamos los conceptos que brindan sustento teórico a esta investigación. En primer lugar describimos los cambios que ha tenido el concepto de desarrollo hasta llegar al desarrollo sostenible, para después argumentar la relación y medición de los elementos de desarrollo humano, bienestar y calidad de vida, considerados conceptos del desarrollo sostenible.

\section{Desarrollo y desarrollo sostenible}

El concepto de desarrollo ha estado ligado tradicionalmente al de crecimiento económico, que busca generar bienestar en la población. Sin embargo, Farge (2007) define bienestar como una serie de disposiciones que dan derecho a los ciudadanos a percibir prestaciones de seguridad social y a contar con servicios organizados como salud y educación en una amplia variedad de situaciones definidas, como necesidad y contingencia. En los años sesenta y setenta, economistas como Amartya Sen, Doyal, Gouhg y Max Neef, cuestionaron la validez de la asociación entre bienestar y crecimiento económico, lo que derivó en la generación de alternativas para comprender y medir el desarrollo, mismo que pasó de centrarse en los medios de producción a poner la mira en la calidad de vida. Este es un concepto de carácter complejo y multidimensional que, desde un enfoque más humanista, incluye los aspectos de la vida tal y como son experimentados por los individuos (Slottje et al., 1991). El estudio de la calidad de vida remite a todas las esferas en que se desarrolla la vida cotidiana de las personas (Solomon et al., 1980).

Desde entonces, y hasta finales de los noventas, el concepto de desarrollo estuvo ligado a la idea de las necesidades básicas de las personas, desde un enfoque de las capacidades, dando paso al Índice de Desarrollo Humano y a los Objetivos de Desarrollo del Milenio expresado en la Asamblea General de las Naciones Unidas llevada a cabo en la Cumbre Río+20:

Es necesario lograr el desarrollo sostenible promoviendo un crecimiento sostenido, inclusivo y equitativo, creando mayores oportunidades para todos, reduciendo las desigualdades, mejorando los niveles de vida básicos, fomentando el desarrollo social equitativo y la inclusión, y promoviendo la ordenación integrada y sostenible de los recursos naturales y los ecosistemas. (Asamblea General de las Naciones Unidas, 2012, p. 1)

Dichos objetivos fueron evaluados y transformados en los Objetivos de Desarrollo Sostenible en el año 2015, cuando comenzó un pacto mundial 
guiado por un concepto de desarrollo que pretende comprender "las interacciones entre tres sistemas complejos: la economía mundial, la sociedad global y el medio ambiente físico de la Tierra" (Sachs, 2015, p. 19).

Jeffrey Sachs (2015) señala que el desarrollo sostenible busca la construcción de un mundo donde el progreso económico esté extendido y la pobreza extrema eliminada; donde la confianza social esté afianzada en políticas públicas que busquen el refuerzo de las comunidades y que el medio ambiente esté protegido del mismo humano. Para lograrlo, el enfoque debe ser holístico y debe incluir al estado. Por ello, hablar de una ciudad desarrollada implicaría no nada más que esta sea económicamente próspera, sino también socialmente inclusiva, ambientalmente sostenible y bien gobernada (Sachs, 2015). El Banco Interamericano de Desarrollo (2016) menciona que una ciudad sostenible:

\footnotetext{
Es aquella que ofrece una adecuada calidad de vida a sus ciudadanos, minimiza sus impactos al medio natural, preserva sus activos ambientales y físicos para generaciones futuras y promueve el desarrollo económico y la competitividad. De la misma manera, cuenta con un gobierno con capacidad fiscal y administrativa para llevar a cabo sus funciones urbanas con la participación activa de la ciudadanía.
}

Para efectos de este trabajo utilizamos esta definición de ciudad sostenible que pretende resolver problemáticas humanas y convertirse en un camino para generar bienestar y elevar el nivel de calidad de vida de quienes componen a una comunidad, al tiempo que procuran mantener y renovar los recursos naturales.

\section{Desarrollo humano y bienestar}

El enfoque del Desarrollo Humano se centra en las personas, siendo ellas el objetivo de todos los esfuerzos destinados a conseguir la prosperidad de un país o una sociedad. Consiste en poner condiciones para desarrollar capacidades de las personas y generar así mayor libertad, es decir, la oportunidad de poder usar las capacidades para que puedan vivir una vida que valoren (United Nations Development Programme, 2015).

Las dimensiones esenciales del enfoque de desarrollo humano se clasifican en dos. La primera dimensión mejora directamente las capacidades humanas, como una vida larga y saludable, adquisición de conocimientos valiosos y un nivel de vida digno. Y la segunda dimensión crea condiciones para el desarrollo humano, como participación en la vida política y en la comunidad, sostenibilidad ambiental, seguridad humana y derecho e igualdad de género (United Nations Development Programme, 2015). 


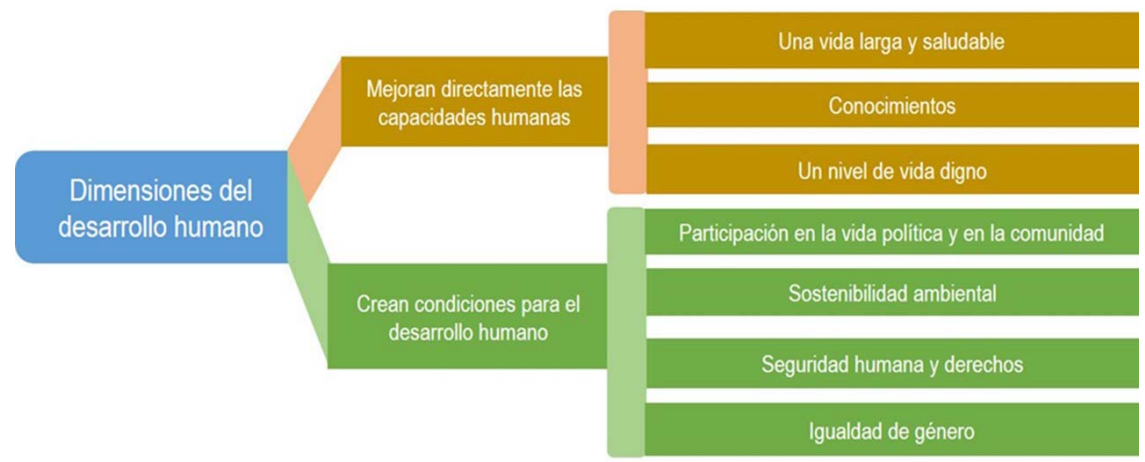

Diagrama 1 - Dimensiones del desarrollo humano

Fuente: United Nations Development Program, 2015

El problema de equiparar bienestar o calidad de vida con libertad es la dificultad para medir dichos conceptos debido a la amplia variedad de significados que estos tienen. Por ello, existen diversos enfoques que han intentado abordar el tema de medir el bienestar y la calidad de vida. Uno de ellos es el Producto Interno Bruto (PIB) como medida de progreso, sin embargo, fue criticado duramente ya que no necesariamente un PIB alto refleja una mejora de la calidad de vida de los habitantes. Otro enfoque utilizado es el Índice de Desarrollo Humano (IDH) como medida de bienestar, en donde la meta a alcanzar es la ampliación de capacidades de las personas, y no un aumento de la utilidad y la satisfacción económica (Griffin, 2019). Este índice presenta una alternativa de medición basada en indicadores de ingreso, esperanza de vida y educación. Por otro lado, la OCDE (2015) presentó una propuesta de medición de bienestar multidimensional que cubre distintos aspectos de la vida los cuales van del compromiso cívico a la vivienda, del ingreso familiar al balance vida trabajo, y de las competencias y habilidades a la salud.

$\mathrm{Al}$ analizar estas condiciones de bienestar se vuelve imprescindible tener claro el contexto donde se encuentran las personas. La ciudad de Cancún, tiene como característica ser un "enclave" turístico (Cardoso \& Faletto, en Hiernaux, 2013). Falero (2015) señala que en los territorios enclaves se habilitan condiciones económicas especiales para el desarrollo de actividades económicas por parte de las empresas trasnacionales, que en este caso son las cadenas hoteleras. También señala que es posible hablar de enclaves turísticos cuando el capital trasnacional privatiza territorios o delimita a los mismos utilizando cadenas hoteleras o turoperadores, tal como es el caso de Cancún. En estos enclaves, el papel del estado es de mediador entre los recursos y las trasnacionales, más que el bienestar comunitario. 
Considerando los factores anteriores desarrollamos el modelo de medición de la sostenibilidad y calidad de vida para ciudades turísticas (McCoy \& Aguiar, 2017), enmarcado en el enfoque de sostenibilidad explicado, y diseñado especialmente para los espacios urbanos de carácter turístico que se encuentran en rápido crecimiento.

\section{Resultados}

De acuerdo a los datos obtenidos de la investigación exploratoria, el perfil demográfico de la muestra arroja la edad promedio de 38 años, la edad mínima fue de 18 y la máxima de 83 años. El 34.8\% de la muestra tiene entre 36 a 45 años, el $20 \%$ entre 26 a 35 años, el 19\% entre 46 a 55 años, otro $19 \%$ entre 17 a 25 años, el 5.9\% está entre 56 a 65 años y 1.2\% tiene más de 65 años.

El 42.1\% de la muestra encuestada tiene entre 16 y 25 años radicando en Cancún como muestra la tabla 5. Es necesario mencionar que solo un $11.8 \%$ tiene hasta 5 años viviendo en Cancún.

Tabla 5 - Años radicando en la ciudad de Cancún Q. Roo, México

\begin{tabular}{ccc}
\hline Años radicando en Cancún & Porcentaje válido & Frecuencia \\
\hline Hasta un año & 1.8 & 7 \\
De 1 a 5 años & 10 & 40 \\
De 6 a 10 años & 16 & 64 \\
De 11 a 15 años & 11.5 & 46 \\
De 16 a 20 años & 24.8 & 99 \\
De 21 a 25 años & 17.3 & 69 \\
De 26 a 30 años & 10 & 40 \\
De 31 a 35 años & 4 & 16 \\
Más de 35 años & 4.8 & 19 \\
\hline
\end{tabular}

Fuente: elaboración propia, número de caso igual a 400

Del total de la muestra, $37.7 \%$ cuenta con preparatoria, $33.3 \%$ tiene licenciatura, $19.2 \%$ cuentan con secundaria, el $8.6 \%$ con primaria, $0.7 \%$ cuentan con maestría, $0.2 \%$ cuenta con algún diplomado y $0.2 \%$ no tiene estudios.

En cuanto a su estado civil el $47.5 \%$ es casado, el $29.0 \%$ soltero, $11.12 \%$ divorciado, $9.0 \%$ se encuentra en unión libre y $3.4 \%$ son viudos. El $88.6 \%$ vive con su familia, el $9.9 \%$ viven solos, el $1.0 \%$ con amigos y el $0.5 \%$ con otros. 
En cuanto a su ocupación el $54.1 \%$ es empleado, el $23.7 \%$ es ama de casa, el $11.6 \%$ tiene negocio propio, el $5.9 \%$ son profesionista, el $2.0 \%$ son desempleados y el $2.7 \%$ otro.

Los datos muestran el perfil demográfico de la población en la entidad es mayoritariamente joven en edad laboral productiva, que a pesar del factor migración, comienza a registrar un grado de consolidación como ciudad, ya que un $42 \%$ de la muestra tiene radicando en la ciudad entre 16 y 25 años. En relación a está consolidación otro dato que abona a la misma es que el $88.6 \%$ vive con su familia. La preparación de la población también se encuentra relacionada a la juventud de la entidad ya que el $71 \%$ cuenta con educación media o media superior lo que facilita la empleabilidad de la misma en puestos operativos y también al hecho del bajo nivel de desempleo existente. El 11.6\% cuenta con su negocio y $54.1 \%$ prefieren ser empleados.

El resultado de la dimensión de sostenibilidad ambiental es de un $48.40 \%$. Cada subtema se muestra en la tabla 2.

En la dimensión de sostenibilidad ambiental la plataforma arroja en el tema de agua un $72.91 \%$ y el indicador de cobertura de agua es de $96.70 \%$, esto concuerda con los resultados de la muestra, que señala que el $99.3 \%$ de los encuestados cuentan con un servicio de agua potable. La muestra también proporcionó que el gasto promedio bimestral de agua es $\$ 283.53$ mxn. (\$15 USD).

El tema de gestión de residuos sólidos presenta un resultado de $85.53 \%$, la plataforma arroja que el indicador de cobertura de recolección de basura es de $83.91 \%$. Y la muestra menciona que la frecuencia del servicio de recolección de basura pasa diariamente: una vez al día $49.6 \%$, cada tercer día $38.7 \%$, frecuencia irregular $10.0 \%$ y no contestó $1.7 \%$.

El tema de vulnerabilidad a desastres hidrometeorológicos (considerados naturales) es de $56 \%$, el indicador de sensibilidad a desastres naturales es de $50 \%$, explicado en tanto que $39 \%$ de la muestra lleva viviendo en la ciudad menos de 15 años, y no ha habido ningún huracán en los últimos 14 años.

El tema de saneamiento y drenaje es de $-37.21 \%$, en donde el indicador de cobertura de saneamiento la plataforma arroja un $79 \%$ y la efectividad de drenaje es $-271.43 \%$. Contrastándolo con las respuestas de la muestra, el $84.5 \%$ cuenta con drenaje y el $15.5 \%$ con fosa séptica. Cuando les preguntamos si sufren inundaciones en su casa el $71.5 \%$ mencionó que no y el $13 \%$ que sí. De este $13 \%$ el $38.0 \%$ mencionó que las inundaciones fueron algo grave, el $28.0 \%$ poco grave, el $20 \%$ grave y el $14.0 \%$ muy grave.

En relación a la situación del drenaje, si bien el indicador de cobertura de saneamiento muestra un porcentaje cercano al $80 \%$, la efectividad no es tal porque el municipio realiza la obra de drenaje. Sin embargo, el trámite 
y la obra de conexión son del particular, en este caso de los ciudadanos, que en ocasiones se conectan ya sea a una fosa séptica, misma que requiere un tratamiento de saneamiento anual o tienen otros métodos para deshacerse de sus desechos.

En relación a las inundaciones observamos que los trabajos de desazolve realizados a partir del año 2015 en algunas colonias han surtido efecto porque las inundaciones no son de la gravedad como las registradas en el pasado. Lo anterior también está relacionado con las mejoras en la recolección de la basura, dónde si bien aún existen colonias con una frecuencia irregular de recoja, por el contrario, hay un $85,3 \%$ de zonas en las que el servicio pasa diario o cada tercer día, manteniendo las calles limpias y coadyuvando a disminuir las inundaciones. Sin embargo, el trasfondo de los residuos va más allá de la frecuencia del servicio de recoja ya que también se relaciona con la limitada o escasa práctica de separación y reciclaje de residuos en la ciudad.

El tema de energía arrojó un $64.75 \%$, el indicador de cobertura energética es de $111.56 \%$, corroborado con el resultado de la muestra ya que un $98.6 \%$ cuenta con luz y el promedio de gasto bimestral es de $\$ 894.29 \mathrm{mxn}$. (\$47.66 USD).

La cobertura de energía eléctrica, es alta pero es importante señalar que depende de una institución federal, con mayor cantidad de recursos que el municipio por un lado. Los predios y colonias reciben el servicio independientemente de que este municipalizado o no, situación que con el resto de servicios no sucede así.

Los resultados de la dimensión urbana arrojan una calificación de $14.01 \%$. Cada tema, subtema e indicador se muestra en la tabla 1.

La plataforma indica que el tema de seguridad está en $-113.2 \%$ y el indicador sobre la confianza ciudadana en materia de seguridad es de $-13.6 \%$. Contrastándolo con los resultados de la muestra preguntamos a los encuestados si se sienten seguros en la ciudad y el $34.2 \%$ contestaron estar en total desacuerdo, $26.8 \%$ en desacuerdo, $16.2 \%$ ni de acuerdo ni en desacuerdo, $15.70 \%$ de acuerdo, $5.4 \%$ total de acuerdo y $1.7 \%$ no sabe.

Cuando preguntamos si él o ella o alguien de su familia ha sido víctima de algún delito en los últimos 12 meses, 17.9\% contestó que sí, 78.5\% que no y $3.6 \%$ no contestaron.

En cuanto al tema de uso de suelo/ordenamiento del territorio está en un -73.37por ciento, el indicador de áreas verdes y recreación está en cero\%. Ante la pregunta realizada en la encuesta $i$ “cuáles son los sitios que más visitan"? los participantes respondieron parques y playas.

El tema de desigualdad urbana arrojado por el modelo de medición de la sostenibilidad y calidad de vida para ciudades turísticas (McCoy \& Aguiar, 2017), es de 55.32\%, y el indicador de desigualdad de los ingresos 
está en un $45.0 \%$. Podemos relacionar que la baja estructura salarial impacta en la calidad de vida la comunidad (tabla 6).

Tabla 6 - Ingresos familiares de la muestra

\begin{tabular}{ccc}
\hline Ingreso familiar & Frecuencia & Porcentaje \\
\hline 20,339 a 44,334 & 42 & $10 \%$ \\
14,950 a 20,338 & 39 & $10 \%$ \\
11,857 a 14,949 & 35 & $9 \%$ \\
9,621 a 11,856 & 49 & $12 \%$ \\
7,972 a 9,620 & 50 & $12 \%$ \\
6,505 a 7,971 & 59 & $14 \%$ \\
5,245 a 6,504 & 56 & $14 \%$ \\
3,932 a 5,244 & 44 & $11 \%$ \\
2,333 a 3,931 & 24 & $6 \%$ \\
hasta 2332 & 11 & $3 \%$ \\
Total & 409 & $100 \%$ \\
\hline
\end{tabular}

Fuente: elaboración propia

La inseguridad se ha convertido en una problemática importante en Cancún y los datos sirven como evidencia de lo que se vive desde el año 2015 en la comunidad. Esa misma inseguridad se refuerza con el abandono de espacios públicos y la poca cantidad de áreas verdes y de recreación por habitante de acuerdo a la Organización Mundial de la Salud. Si bien existen playas públicas estas se encuentran en la zona hotelera, lo que representa un costo para la población debido al transporte y además muchos accesos públicos han sido bloqueados para personas que no se encuentran hospedadas en hoteles del área.

El tema de desigualdad urbana refuerza el hecho de que para muchas familias cancunenses representa una fuerte erogación el disfrutar un día de playa, dado que sus ingresos son justos para las necesidades que se presentan en una ciudad de vida cara como es la estudiada.

El indicador para conexiones a internet es de 310.8\%. La muestra arroja que el $87.8 \%$ cuenta con internet en su casa, mientras que $12.2 \%$ no. Además, durante la encuesta les preguntamos si cuentan con internet en su celular y el 85.1 por ciento mencionó que sí, mientras que $14.9 \%$ mencionó que no.

En relación al tema de movilidad y transporte el resultado es de $22.12 \%$, en cuanto al índice de congestión vial reducida se encuentra un $43.8 \%$ y la muestra arroja que el tiempo promedio que tarda en llegar al 
trabajo o a la escuela es de 30.98 minutos, el tiempo máximo es de 90 minutos. Esta situación que presenta la movilidad y el transporte, donde las personas pasan hasta hora y media en el transporte debido a lo ineficiente de las rutas en una ciudad que es relativamente pequeña en cuanto a distancias.

El indicador de transporte económico arroja un $-80.0 \%$ y esto se puede corroborar con los resultados de la muestra, ya que el promedio de gasto semanal de transporte para ir a trabajar o estudiar es de $\$ 357.63$ (\$19.06 USD) y el máximo es de $\$ 3,509$ (\$187.01 USD).

El indicador de infraestructura de transporte equilibrado es de $19.7 \%$, la muestra indica que los medios de transporte más usados son autobús público, taxi, combi y auto propio, los cuales varían entre uno y cinco para llegar a su destino.

La dimensión fiscal arrojó un resultado de $37.13 \%$. Consulte la tabla 3 para ver los resultados de los temas e indicadores.

La sostenibilidad turística arroja un resultado de $61.55 \%$ (tabla 4 ). Siendo Cancún una ciudad con vocación turística se observa claramente el buen posicionamiento y la satisfacción que tienen sus visitantes al reportar unos indicadores con altos porcentajes al igual que la concentración ya que al año llegan más de cuatro millones de turistas a Cancún (SEDETUR, 2017).

En cuanto al tema de la población, el indicador de crecimiento de la infraestructura reportó un 57\%. Cuando preguntamos a la muestra si el turismo ha ayudado a traer servicios de infraestructura pública a la región en la que viven, $28.5 \%$ contestaron estar en desacuerdo y $51.9 \%$ de acuerdo, $16.9 \%$ ni a favor ni en contra y $2.7 \%$ no contestaron.

El indicador del nivel de satisfacción del subíndice de la población arrojó un $65.89 \%$ de calificación. Cuando preguntamos a la muestra si les producía satisfacción el nivel de la calidad de turistas que llegan al destino, el $59.3 \%$ está de acuerdo, el $17.5 \%$ en desacuerdo, el $21 \%$ no está a favor ni en contra y 2.2.\% no contesto.

Cancún tiene una clara vocación turística, sin embargo también existe la inconformidad de los ciudadanos al observar cómo se priorizan recursos en la zona hotelera y no en las zonas en las que la ciudadanía habita, lo que genera desagrado en la población y, de alguna manera resignación, porque reconocen que dependen del turismo más no ven los recursos aplicados o resultados de su esfuerzo en su bienestar general.

Finalmente, el valor global de la herramienta de la plataforma del modelo de medición de la sostenibilidad y calidad de vida para ciudades turísticas, arroja un índice de calidad de vida para la ciudad de Cancún de $39.52 \%$, contestando a la pregunta, ¿qué nivel de calidad de vida provee la ciudad de Cancún? La otra pregunta de investigación, ¿es Cancún un cen- 
tro turístico sostenible? Basándonos en esta herramienta metodológica, la dimensión de sostenibilidad ambiental se representa en un $48 \%$, la dimensión de sostenibilidad urbana en un $14 \%$, la dimensión de sostenibilidad fiscal en un $37 \%$ y por último la dimensión de la sostenibilidad turística en un $62 \%$. La tarea para los diferentes actores (gobierno, sociedad, empresas y universidades) es coadyuvar a la sostenibilidad a través de proponer leyes y planes que fomenten la conservación y el cuidado de sus recursos (Brenner et al., 2018) conjuntamente con el desarrollo económico, para ofrecer una adecuada calidad de vida a sus ciudadanos.

\section{Conclusiones}

Hablar de sostenibilidad en comunidades turísticas implica necesariamente la relación de las dimensiones urbana, turística, ambiental y fiscal, que se vinculan mutuamente. En una ciudad como Cancún estas dimensiones están presentes y cada una juega un papel preponderante, sin embargo, estas no están equilibradas, por lo que no podemos hablar de una ciudad sostenible.

Cancún fue desarrollado como un Centro Íntegramente Planeado (CIP) y como un polo turístico sostenible y equilibrado que contemplaba la satisfacción de las necesidades de infraestructura y servicios, tanto para los locales como para los turistas. El objetivo de la investigación fue determinar el nivel de sostenibilidad de la ciudad, sin embargo, podemos afirmar que Cancún no es una ciudad sostenible ya que de acuerdo con el índice que arrojó el modelo de medición de la sostenibilidad y calidad de vida para ciudades turísticas, la ciudad obtuvo en el índice de calidad de vida una calificación de $39.52 \%$, lo que nos indica el bajo impacto que existe en el bienestar de la comunidad.

$\mathrm{Al}$ analizar los datos, encontramos diversas áreas de oportunidad, por ejemplo el área de saneamiento y drenaje (dimensión ambiental, $84.40 \%$ ), tema que requiere una mejora rápida y constante, ya que Cancún tiene una tasa de crecimiento poblacional del $2.5 \%$ anual.

Como mencionamos en los resultados, el indicador de cobertura del drenaje muestra un porcentaje cercano al $80 \%$, sin embargo, la efectividad indicada no es tal, ya que la obligación del municipio es realizar la obra de drenaje, pero los trámites de conexión al mismo son tareas que el particular, en este caso los ciudadanos, deben hacer y por lo general esto no sucede. Es necesario revisar las colonias que no cuentan con conexión al drenaje, que no están municipalizadas o donde el gobierno ya realizó la construcción de la infraestructura de la red de drenaje y a pesar de ello, las familias no se han conectado. Así como buscar estrategias de política 
pública que den solución a esta problemática, ya que dada las condiciones de suelo de la localidad los desechos humanos son vertidos al manto freático contaminándolo.

En cuanto a la energía, el gobierno estatal debe implementar más proyectos sobre energía alternativa y renovable buscando tener un impacto ecológico positivo en la ciudad y así reducir la dependencia de los combustibles fósiles. Máxime cuando existen estudios investigación en entidades locales que proporcionan opciones y estas no han sido tomadas en cuenta.

En el tema de prevención de desastres es necesario advertir que en los últimos 14 años no han ocurrido desastres hidrometeorológicos relacionados con algún evento natural extremo, como un huracán, por lo que ha disminuido la prioridad en relación a sus implicaciones y a la prevención requerida, por lo que sugerimos programas de comunicación para saber qué hacer en caso de un huracán.

Otro tema importante a considerar en la dimensión de sostenibilidad ambiental es urgente realizar campañas de comunicación para fomentar el cambio de conciencia con respecto al manejo de los residuos, fomentando la separación de los mismos desde el origen y no solamente con una endeble estrategia de Reciclatón (centros de acopio de productos reciclables de la ciudadanía) una vez al mes. Consideramos que las acciones deben de ser integrales para que puedan observarse resultados globales en la comunidad.

En la dimensión urbana (14.01\%), es imprescindible que empresas y gobierno sigan trabajando en temas de seguridad, densidad urbana, movilidad y transporte, y gestión pública participativa, ya que Cancún es un polo turístico que atrae a mucha población migrante, y no está preparado para satisfacer las necesidades de la población en constante crecimiento. Si bien Cancún fue el primer centro turístico con un plan maestro, actualmente es urgente e importante plantearse una visión actualizada sobre lo que los ciudadanos desean en los aspectos urbanos mencionados, y de manera conjunta, gobierno, empresas y ciudadanos trabajar para construirla.

También encontramos factores que inciden directamente en la calidad de vida, como por ejemplo, los extensos horarios de trabajo y la baja estructura salarial.

En la dimensión de sostenibilidad fiscal y gobernabilidad (37.13\%), encontramos que el Gobierno Municipal debe modernizar los procesos de gestión pública haciéndolos más eficientes y eficaces para los usuarios, trabajar en transparencia sobre aspectos de la gestión del gasto y la deuda del municipio de Benito Juárez al cual pertenece Cancún y fomentar la participación ciudadana en la elaboración de presupuestos.

La dimensión de sostenibilidad turística (61.55\%), es una de las mejor evaluadas debido a que la ciudad de Cancún tiene vocación turística. Por 
un lado, la sociedad está consciente de que el turismo representa en muchos casos un ingreso importante y por lo tanto la filosofía del buen servicio permea en las prácticas cotidianas de la ciudad. Por lo mismo, los turistas encuentran servicios e infraestructura de primer nivel, y deciden regresar al destino. Sin embargo, no es claro el beneficio que aportan las empresas turísticas en términos de infraestructura y servicios para la comunidad, en ocasiones pareciera que son dos mundos aislados que comparten un mismo espacio cuando la realidad es otra, es un solo universo.

Por lo tanto, Cancún es una ciudad emergente que no resulta ser una ciudad sostenible bajo los parámetros del modelo de medición de la sostenibilidad y calidad de vida para ciudades turísticas. Esto refleja una realidad que lleva a reflexionar sobre los aspectos de mejora para la toma de decisiones, lo que permite una comprensión interrelacionada de los elementos que inciden para que Cancún realmente sea una ciudad sostenible.

Entre las limitantes de este estudio, encontramos la dificultad para obtener ciertos datos, especialmente de la dimensión turística, ya que implica realizar entrevistas a los administradores de las empresas turísticas y contrastarlos nuevamente con la percepción de los turistas y la comunidad. Otro elemento que observamos fue que los datos oficiales, en algunos casos, son más optimistas que la realidad, así como las distintas periodicidades con las que se actualizan estos datos. Es decir, hay datos que se modifican cada diez años con los censos y otros datos que pueden cambiar cada trimestre, como los datos de afluencia turística.

Por último, el modelo de medición de la sostenibilidad y calidad de vida, da pauta para realizar investigaciones futuras sobre dimensiones en donde arrojaban indicadores con resultados bajos, así como las relaciones inter-indicadores obtenidas a partir de las series históricas generadas.

PILIVET AGUIAR ALAYOLA es licenciada en psicología y maestra en desarrollo humano por la Universidad Marista de Mérida, profesora de tiempo completo de la Universidad del Caribe y pertenece al Cuerpo Académico "Sustentabilidad, Desarrollo y Competitividad". Sus temas de investigación versan sobre grupos vulnerables, calidad de vida, derechos humanos y vulnerabilidad. Email: paguiar @ucaribe.edu.mx

CHRISTINE MCCOY CADOR es doctora en desarrollo económico sectorial estratégico por la UPAEP, profesora de tiempo completo de la Universidad del Caribe. Pertenece al Cuerpo Académico "Sustentabilidad, Desarrollo y Competitividad" y sus líneas de investigación son desarrollo económico y calidad de vida; economía urbana y calidad de vida; capacidad de carga turística y desarrollo económico en ciudades turísticas, así como desarrollo económico sustentable. Email: cmccoy@ ucaribe.edu.mx 
LUCILA ZÁRRAGA CANO es doctora en dirección y mercadotecnia por la Universidad Popular Autónoma de Puebla, adscrita al Departamento de Economía y Negocios de la Universidad del Caribe. Líder del Cuerpo Académico "Sustentabilidad, Desarrollo y Competitividad". Sus temas de investigación son modelos de competitividad en empresas turísticas, calidad en el servicio, generación de valor para el mercado interno y externo de las empresas y calidad de vida. Email: lzarraga@ucaribe.edu.mx

\section{REFERENCIAS}

Aguiar Alayola, P. (2018). No todo lo que brilla es oro. En P. Aguiar Alayola, G. Vázquez Flores, L. Díaz Molina \& O. Reyes Hernández. Claroscuros del desarrollo humano. Cancún: Colofón.

Asamblea General de las Naciones Unidas. (2012). El futuro que queremos. Río + 20 Conferencia de las Naciones Unidas sobre el Desarrollo Sostenible, 1-59. Río de Janeiro: Naciones Unidas.

Banco Interamericano de Desarrollo. (2016). Guía Metodológica iniciativa ciudades emergentes y sostenibles: anexo de indicadores de la guía metodológica del Programa de Ciudades Emergentes y Sostenibles. Tercera edición. Descargado de https://publications.iadb.org/publications/spanish/document/ $\mathrm{Gu}$ percentC3percentADa-Metodol percentC3 percentB3gica-Programa-deCiudades-Emergentes-y-Sostenibles-Tercera-edici percentC3 percentB3n-An exo-de-indicadores.pdf.

Brenner, L. (1999). Modelo para la evaluación de la sustentabilidad del turismo en México con base en el ejemplo de Ixtapa-Zihuatanejo. Investigaciones Geográficas 39: 139-158. Descargado de http://www.scielo.org.mx/scielo.php?script =sci_arttext\&pid=S0188-46111999000200010.

Brenner, L., Engelbauer, M., \& Job, H. (2018). Mitigating tourism-driven impacts on mangroves in Cancún and the Riviera Maya, Mexico: An evaluation of conservation policy strategies and environmental planning instruments. Journal of Coastal Conservation 22(4), 755-767.

COESPO Quintana Roo. (2019). Consejo Estatal de Población. Recuperado de Secretaría de Gobierno. Descargado de http:/qroo.gob.mx/sites/default/ files/2017-08/QROO.pdf.

CONAVI-SEDATU. (2019). Sistema Nacional de Indicadores de Vivienda. Recuperado de Protecciones de Población. Descargado de http://sniiv.conavi.gob .mx/Reports/Conapo/Proy_Pob.aspx.

Córdoba Azcárate, M. (2019). Fueling ecological neglect in a manufactured tourist city: Planning, disaster mapping, and environmental art in Cancun, Mexico. Journal of Sustainable Tourism 27(4): 503-521.

Falero, A. (2015). La expansión de la economía de enclaves en América Latina y la ficción del desarrollo: siguiendo una vieja discusión en nuevos moldes. Revista Mexicana de Ciencias Agrícolas 1: 145-157. Descargado de https://www .redalyc.org/pdf/2631/263139243020.pdf. 
Farge, Collazos, C. (2007). El estado de bienestar. Enfoques XIX(1-2): 45-54. Descargado de https://www.redalyc.org/articulo.oa?id=259/25913121005.

FONATUR. (1982). Cancún. Un desarrollo turístico en la costa turquesa. México: FONATUR.

Gobierno del Estado de Quintana Roo. (2018). Indicadores censales del Estados de Quintana Roo. Chetumal: Gobierno del Estado de Quintana Roo.

Griffin, K. (2019). Desarrollo humano: origen, evolución e impacto. Descargado de https://nanopdf.com/download/desarrollo-humano-origen-evolucion-eimpacto_pdf.

Hiernaux, D. (2013). Las ciudades y las regiones. En B. R. Ramírez Velázquez \& E. Pradilla Cobos, Teorías sobre la ciudad en América Latina (pp. 53-81). México: UAM.

INEGI. (2017). Anuario estadístico y geográfico de Quintana Roo 2017. México: INEGI.

INEGI. (2018). Cuéntame. Descargado de http://cuentame.inegi.org.mx/monogra fias/informacion/qroo/territorio/div_municipal.aspx?tema=me\&e=23.

McCoy Cador, C. (2015). Propuesta para recuperar la perspectiva de destino turístico sustentable con base en el análisis de su desempeño y evolución a través de la metodología de Capacidad de Carga Turística: Caso Cancún (Tesis Doctoral). Cancún: UPAEP.

McCoy Cador, C., \& Aguiar Alayola, P. (2017). Resultados indice de sustentabilidad y calidad de vida. Cancún: Integra.

McCoy Cador, C., \& Sosa Ferreira, P. (2016). Causas y efectos de un destino no sustentable: Caso Playas Públicas de Cancún, Quintana Roo. El Periplo Sustentable 31. Descargado de http://www.scielo.org.mx/pdf/eps/n31/1870-9036eps-31-00006.pdf.

Numbeo. (2020) Costo de vida. Descargado de https://es.numbeo.com/coste-devida/pa percent25C3 percent25ADs/México.

OCDE. (2015). How's Life? Measuring Well-being. OCDE Publishing Paris,OCDE. https://doi.org/10.1787/how_life-2015-en.

ONU. (2019). Reporte Nacional de Prosperidad Urbana en México 2019. Descargado de http://70.35.196.242/onuhabitatmexico/cpi/Reporte-CPI-2019.pdf.

PNUD. (2014). Índice de Desarrollo Humano Municipal en México: una nueva metodología. México: PNUD.

Programa de Desarrollo Urbano del Centro de Población de Cancún. (2018). Programa de Desarrollo Urbano del Centro de Población Cancún, Municipio Benito Juárez, Quintana Roo (2014-2030). Descargado de http://seduvi .qroo.gob.mx/pdus/36-PDU percent20DEL percent20CENTRO percent20DE percent20POBLACION percent20CANCUN percent20BENITO percent20JUAREZ percent20QUINTANA percent20ROO percent202014-2030(1).pdf. Sachs, J. (2015). La era del desarrollo sostenible. España: Deusto.

Secretaría de Desarrollo del Gobierno de Quintana Roo. (2020). SEDE. Descargado de https://qroo.gob.mx/sede/siec/poblacion-ocupada.

SEDETU. (2019). Informe de operativos zonas irregulares. Cancún: SEDETU.

SEDETUR. (2017). Indicadores turísticos 2017. Secretaría de Turismo del Estado de Quintana Roo. Descargado de http://sedeturqroo.gob.mx/ARCHIVOS/ 
indicadores/Indicadores percent20Tur percent20- percent20Diciembre percent202017.pdf.

Slottje, D. J., Scully, G. W., Hirschberg, J. G., \& Hayes, K. J. (1991). Measuring the quality of life across countries: A multidimensional analysis. Westview: Boulder.

Solomon, E. S., Bouchouchi, N. V., Denisov, V., Hankiss, E., Mallman, C. A., \& Milbrath, L. W. (1980). UNESCO's policy-relevant quality of life research program. In A. Szalai \& F. M. Andrews (Eds.), The quality of life: Comparative studies (pp. 223-233). London: Sage Publications.

United Nations Development Programme. (2015) ¿Qué es el desarrollo humano? Obtenido de Departamento de comunicación de la Oficina del Informe sobre el Desarrollo humano. Human Development Report. Descargado de http://hdr .undp.org/en/node/2228.

\title{
Are tourist cities sustainable?: The case of Cancun
}

\section{Pilivet Aguiar Alayola, Christine McCoy Cador, Lucila Zárraga Cano}

\begin{abstract}
The city of Cancun, Quintana Roo, Mexico, is characterized by its tourism activity due to the tourist attractions it offers. The objective of this research is to determine the level of sustainability according to urban, environmental, fiscal, and tourism dimensions. The research methodology consists of results obtained from the model for measuring sustainability and quality of life for tourist cities, through secondary and primary data, and through an exploratory study on a sample of 416 inhabitants of the city of Cancun, Quintana Roo. The results show that Cancun has areas for improvement to contribute to sustainability.
\end{abstract}

Keywords: development, emerging cities, quality of life, sustainability, tourist cities

\section{Des villes touristiques durables? Le cas de Cancun}

\section{Pilivet Aguiar Alayola, Christine McCoy Cador, Lucila Zárraga Cano}

Résumé: La ville de Cancun, au Quintana Roo, Mexique, se caractérise par son activité touristique, en raison des attractions qu'elle offre dans ce domaine. L'objectif de cette recherche est de déterminer le niveau de durabilité des dimensions urbaine, environnementale, fiscale et touristique. La méthodologie s'appuie sur les résultats obtenus à partir d'un modèle de mesure de la durabilité et de la qualité de vie des villes touristiques obtenu à travers des données secondaires et primaires pour une étude exploratoire d'un échantillon de 416 habitants de la ville de Cancun. Les résultats montrent que Cancun présente des domaines à améliorer pour contribuer à la durabilité.

Mots clés: qualité de vie, villes émergentes, villes touristiques, développement, durabilité. 